\title{
Performance analysis and design implementation of a novel polymer hollow fiber liquid desiccant dehumidifier with aqueous potassium formate
}

\author{
Nan Zhang ${ }^{1}$, Xiangjie Chen ${ }^{2,3}$, Yuehong $\mathrm{Su}^{2}$, Devrim Aydin ${ }^{4}$, Hongfei Zheng ${ }^{1, *}$, Hongyu $\mathrm{Bai}^{2}$, \\ Apostolos Georgakis ${ }^{5}$, Hasila Jarimi ${ }^{2}$, Saffa Riffat ${ }^{2}$ \\ ${ }^{1}$ School of Mechanical Engineering, Beijing Institute of Technology, Beijing 100081, China \\ ${ }^{2}$ Department of Architecture and Built Environment, the University of Nottingham, University \\ Park, Nottingham, NG7 2RD, UK. \\ ${ }^{3}$ Department of Energy and Power Engineering, University of Shanghai for Science and \\ Technology, Jungong Road No. 516, Shanghai, 200031, China \\ ${ }^{4}$ Department of Mechanical Engineering, Eastern Mediterranean University, G. Magosa, \\ TRNC Mersin 10, Turkey. \\ ${ }^{5}$ School of Computing and Engineering, University of West London, W5 5RF, UK. \\ Contact: Xiangjie Chen; Email:xiangjie.chen@nottingham.ac.uk ; Hongfei Zheng; \\ Email:hongfeizh@bit.edu.cn
}

\begin{abstract}
A novel cross-flow liquid desiccant polymer hollow fiber dehumidifier (PHFD) is investigated numerically in this paper.

The main objective of this research is to simulate, validate the numerical model for future design implementations. The experimental verified simulation data will be used to develop a set of design and implementation tables and charts as the guidance for selecting the number of fibres and the solution-to-air mass flow ratio of the PHDF under given conditions. A numerical model is developed to simulate the performance of the proposed innovative dehumidifier. This model is validated against three sets of data, i.e, the experimental obtained testing results, analytical correlations and the modelling results from the literature. The influence of various operating conditions such as inlet air properties (i.e. velocity, relative humidity) and inlet solution properties (i.e. temperature, concentration, mass flow rate) on the dehumidification sensible, latent, and total effectiveness, moisture removal rate are numerically analyzed. Dimensionless parameters including the number of heat transfer unit (NTU) and the number of mass transfer unit $\left(\mathrm{NTU}_{\mathrm{m}}\right)$, the solution to air mass flow rate ratio $\left(\mathrm{m}^{*}\right)$, and the air to solution specific humidity ratio $\left(\omega_{r}^{*}\right)$ have been used to evaluate the system performance. The results show that the increase in NTU and $\mathrm{NTU}_{\mathrm{m}}$ lead to a substantial change in dehumidification effectiveness. When the NTU increases from 0.47 to 7 , the sensible effectiveness rises from 0.35 to 0.95 . Increasing $\omega_{r}^{*}$ is another good option for increasing the amount of the absorbed moisture without influencing the latent effectiveness. For an increase of $\omega_{r}^{*}$ from 1.4 to 2.2, the air inlet and outlet specific humidity difference varies in the range of $0.008 \mathrm{~kg} / \mathrm{kg}$ and $0.018 \mathrm{~kg} / \mathrm{kg}$.
\end{abstract}

Keywords: Polymer hollow fibre dehumidifier, potassium formate solutions, heat transfer, mass transfer, numerical analysis, experimental validation, performance implementation 


\section{Introduction}

Around $40 \%$ and $50 \%$ of the EU's total energy and electricity consumption, respectively, takes place in buildings [1]. The majority of this comes from the combustion of fossil fuels, contributing to approximate $36 \%$ of the EU's total carbon emissions [2]. By 2025, the installed air-conditioning capacity in Europe is predicted to further increase by $50 \%-60 \%$ compared with that in 2010 [3]. The above situation has fueled research into energy-efficient and environmentally-friendly air-conditioning systems.

Dehumidification is an inseparable part of air conditioning, both for commercial and residential cooling, and for humidity control in a wide range of industries (e.g. food, textile, wood processing, printing, and crop drying). Recent research into efficient dehumidifiers has been growingly focusing on liquid desiccant-integrated processes [4], and evaporative cooling [5, 6]. This approach introduces important advantages compared with the conventional vapour compression (VC) systems. Firstly, it does not require refrigerants such as CFCs and HFCs, which are known to be detrimental to ozone depletion and global warming. Secondly, it results in energy savings of around 30\% [5] by avoiding the deep-cooling-and-reheating cycles (VC systems remove moisture from the air by cooling it below its dew point so that water vapour condenses on a cooling coil, and then reheat the dehumidified air to reach the desired temperature). Liquid desiccant-based systems dehumidify the air by utilizing the natural hygroscopic properties of desiccant materials, i.e. their ability to absorb moisture. Finally, thanks to their lower consumption, liquid desiccant dehumidifiers can easily be powered by renewable energy (e.g. solar, wind) [7-10], further reducing carbon emissions.

Central to the design of liquid desiccant dehumidifiers is the flow pattern in which the incoming humid air gets in contact with the moisture absorbing material. There are two broad types of dehumidifier designs: direct contact [11-17] and indirect contact [18-21]. Direct contact simply exposes the liquid desiccant to the flowing air. A two stage liquid desiccant dehumidifier proposed by Xiong et al. [22] showed a double fold thermal performance improvement compared with a conventional dehumidifier. A fin-tube type internally-cooled liquid desiccant dehumidifier was explored by Luo et al. using experimental analysis [23] and CFD modeling [24]. Ou et al. [25], conducted experimental and analytical studies on a combined system with a cooling coil, obtaining $22.3 \%$ of energy savings.

A disadvantage of direct contact is that the air passing over the liquid dessicant results in droplets of the desiccant migrating across the dehumidifier. To mitigate this, thin membrane plate dehumidifiers with different configurations have been studied by various researchers. A cross flow membrane contactor was analyzed by Das and Jain [26] using $\mathrm{LiCl}$ as the liquid desiccant. The results indicated that the reduced air channel gap within the membrane contactor lead to improved energy efficiency. Ge et al. [27-30] presented a counter-cross-flow singleplate membrane contactor with an air gap of $5 \mathrm{~mm}$ using again $\mathrm{LiCl}$ as the desiccant. Their numerical and experimental results confirmed that the solution concentration and the moisture flow rate were the main factors for efficient moisture removal. Moghaddam et al.[31-34] tested an air-to-liquid membrane energy exchanger using $\mathrm{LiCl}$. The results showed that the dehumidifier effectiveness (both sensible and latent) was sensitive to the concentration of the inlet solution. 
Despite the extensive research on the performance of various packed beds $[16,17,22,25]$ or thin membrane plate dehumidifiers [27,31], the liquid droplet carryover problem could not be solved. Since most liquid desiccants $\left(\mathrm{LiCl}, \mathrm{CaCl}_{2}\right.$ and $\left.\mathrm{LiBr}\right)$ are corrosive and harmful to health, the spreading, as well as the proper subsequent removal of their carryovers becomes a major problem. In order to address this, permeable polymer hollow fiber dehumidifiers (PHFD) have been proposed as an alternative for direct contact dehumidifiers. Due to the microscopic size of its pore (less than $100 \mu \mathrm{m}$ ) [35], the hollow fibre allows the moisture of the incoming air to penetrate through its porous wall, while preventing any liquid desiccant droplets from getting in contact with the processed air. Moreover, the small inside diameter (less than $0.1 \mathrm{~mm}$ ) of the polymer hollow fiber leads to significantly enhanced surface contact areas, which can be regarded as another great advantage of the PHFD. A numerical simulation model for a hollowfiber dehumidification system was proposed by Zhang et al. [36]. They concluded that the dehumidifier's effectiveness and dimensionless parameters were influenced by the varying air flow rate. Huang et al. [37] analyzed the coupled heat and mass transfer in parallel-plate membranes by numerical analysis. Their findings showed that the boundary conditions were non-uniform both in the air side and the solution side. A CFD package-FLUENT module was set-up by Zhang et al. [38]. Their analytical data indicated that the packing ratio had a major impact on the flow distribution. The above team, has recently also worked on integrating liquid desiccant-based membranes into heat pumps [39, 40] and heat recovery systems [41].

The research work presented in this paper aims to bridge the following research gaps: (1) As summarized in Table 1, the work published in the field of hollow fiber integrated dehumidification systems has mostly focused on theoretical modelling [36-39], with hardly any experimental results. Attempts have been made to obtain the overall heat and mass transfer coefficients for a polymer hollow fiber integrated shell-and-tube heat exchanger [42]. Due to the difficulties in the manufacturing process of PHFD (especially related to potting the hollow fiber bundles), very limited effort has been made to validate the models against experimental testing results. (2) The dehumidification capacity of PHFD with aqueous potassium formate $(\mathrm{KCOOH})$ as the liquid desiccant has not been adequately addressed in the literature. With its advantages of low price, low toxicity and low corrosiveness compared with other liquid desiccants [43], the aqueous potassium formate solution is a preferable, environmentally friendly liquid desiccant. The associated higher vapour pressure of $\mathrm{KCOOH}$ solutions means that smaller amounts of energy are required for the regeneration stage [43], leading to a great energy saving potential for the proposed PHFD. (3) Most importantly, previous modelling works presented in the literature are largely based on specific working conditions and certain PHFD module configurations, which can hardly be duplicated practically in the design of PHFD modules for arbitrarily given operating conditions. (4) The effects of different fiber numbers on the dehumidification performance of PHFD have not been investigated to date. A detailed summary of previous research work and the research gap this paper is aiming to bridge is shown in Table 1.

This paper introduces numerical and experimental investigations of a polymer hollow fiber integrated dehumidifier (PHFD) with a potassium formate solution. It starts with numerical evaluations of heat and mass transfer in such cross-flow liquid desiccant PHFDs. As opposed to thin plate membrane contactors [31-34], the developed model takes into consideration the 
porous and permeable feature of the polymer hollow fibers. Firstly, the derived mathematical model was verified against three sets of data, i.e. experimental testing results, analytical results, and published simulation results. Then, the impact of various operating conditions, i.e. the inlet air properties (velocity, relative humidity), and the inlet solution properties (concentration, mass flow rate, temperature) on: (a) the dehumidification effectiveness (sensible, latent, and total), (b) the moisture removal rate, and (c) the outlet parameters (air temperature and specific humidity), were numerically calculated and analyzed using the verified model. Dimensionless parameters including the number of heat transfer unit (NTU) and number of mass transfer unit $\left(\mathrm{NTU}_{\mathrm{m}}\right)$, the solution-to-air mass flow ratio $\left(\mathrm{m}^{*}\right)$, the air-to-solution specific humidity ratio $\left(\omega_{r}{ }^{*}\right)$ have been employed to evaluate the dehumidification performance of the proposed PHFD. Finally, the effects of fiber number on the dehumidification performance have been analyzed. Based on the numerical modelling, a set of PHFD performance tables and charts have been developed and verified against experimental results [44]. These can serve as a guidance for the selection of appropriate number of fibres and the solution-to-air mass flow ratio of the PHDFs under given conditions. With no iterative calculation required, this would give the designers great convenience. The outcomes in the form of tables and charts can be used in the design of aqueous KCOOH based PHFD. The research approach in this paper can also be adopted for other types of liquid desiccants and PHFD configurations.

Table 1 Summary of the existing works and the research gap bridged by the present research

\begin{tabular}{|c|c|c|c|c|c|c|}
\hline Reference & $\begin{array}{c}\text { Dehumidifier } \\
\text { type }\end{array}$ & $\begin{array}{l}\text { Flow } \\
\text { patter }\end{array}$ & $\begin{array}{l}\text { Direct/indirect } \\
\text { contact } \\
\text { between air } \\
\text { and liquid } \\
\text { desiccant }\end{array}$ & $\begin{array}{l}\text { Numerical/ } \\
\text { Experimental } \\
\text { investigation }\end{array}$ & $\begin{array}{l}\text { Desiccant } \\
\text { solution }\end{array}$ & $\begin{array}{c}\text { Research methodology and } \\
\text { conclusion }\end{array}$ \\
\hline $\begin{array}{l}\text { Peng and } \\
\text { Zhang [7] }\end{array}$ & Packed bed & $\begin{array}{l}\text { Parallel } \\
\text { flow }\end{array}$ & Direct & Numerical & $\mathrm{LiCl}$ & $\begin{array}{l}\text { The analytical results were proved to } \\
\text { agree well with modelling data. }\end{array}$ \\
\hline Li et al. [8] & Packed bed & $\begin{array}{l}\text { Parallel } \\
\text { flow }\end{array}$ & Direct & Both & $\mathrm{LiCl}$ & $\begin{array}{l}\text { The proposed simplified model } \\
\text { agreed well with the experimental } \\
\text { data. }\end{array}$ \\
\hline Xiao et al. [9] & Packed bed & $\begin{array}{l}\text { Counter } \\
\text { flow }\end{array}$ & Direct & Numerical & $\mathrm{LiCl}$ & $\begin{array}{l}\text { The proposed outdoor air liquid } \\
\text { desiccant system could be adopted } \\
\text { for humid and hot climates, with the } \\
\text { system performance improvement of } \\
19.9-38.4 \% \text {. }\end{array}$ \\
\hline $\begin{array}{l}\text { Wang et al. } \\
{[16]}\end{array}$ & Packed bed & $\begin{array}{l}\text { Parallel } \\
\text { flow }\end{array}$ & Direct & Both & $\mathrm{LiCl}$ & $\begin{array}{l}\text { The work conducted was mainly } \\
\text { focused on the input and output data } \\
\text { for system control and optimization, } \\
\text { therefore no iterative process was } \\
\text { involved. }\end{array}$ \\
\hline Wu et al. [17] & Packed bed & $\begin{array}{l}\text { Counter } \\
\text { flow }\end{array}$ & Direct & Numerical & $\mathrm{LiCl}$ & $\begin{array}{l}\text { The control strategy applied in this } \\
\text { work avoids the continuous solution } \\
\text { exchange, which allowed a series of } \\
\text { dehumidifiers to work together for } \\
\text { large scale building applications. }\end{array}$ \\
\hline
\end{tabular}




\begin{tabular}{|c|c|c|c|c|c|c|}
\hline $\begin{array}{l}\text { Xiong et al. } \\
\text { [22] }\end{array}$ & Packed bed & $\begin{array}{l}\text { Counter } \\
\text { flow }\end{array}$ & Direct & Numerical & $\mathrm{CaCl}_{2}$ & $\begin{array}{l}\text { The two-stage dehumidification } \\
\text { system was shown to offer } \\
\text { significant performance } \\
\text { improvement, with thermal COP of } \\
0.73 \text { and exergy efficiency of } 23 \% \text {. }\end{array}$ \\
\hline $\begin{array}{l}\text { Luo et al. [23, } \\
24]\end{array}$ & $\begin{array}{l}\text { Fin tube heat } \\
\text { exchanger }\end{array}$ & $\begin{array}{l}\text { Counter } \\
\text { flow }\end{array}$ & Indirect & Both & $\mathrm{LiCl}$ & $\begin{array}{l}\text { The proposed fin type dehumidifier } \\
\text { was made of light weight, corrosion } \\
\text { resistant metal, which proved to offer } \\
\text { dehumidification efficiency above } \\
60 \% \text {. }\end{array}$ \\
\hline $\begin{array}{l}\text { Moghaddam } \\
\text { et al. [31] }\end{array}$ & $\begin{array}{l}\text { Thin plate } \\
\text { membrane } \\
\text { energy } \\
\text { exchanger }\end{array}$ & \begin{tabular}{|l|} 
Counter- \\
cross \\
flow
\end{tabular} & Indirect & Both & $\mathrm{LiCl}$ & $\begin{array}{l}\text { Made from semi-permeable } \\
\text { membrane panels, the dehumidifier } \\
\text { was designed with } 2.4 \mathrm{~mm} \text { solution } \\
\text { channel sandwiched between two } \\
\text { solution panels. }\end{array}$ \\
\hline $\begin{array}{l}\text { Zhang et al. } \\
{[36] \text { and }} \\
\text { Huang et al. } \\
{[37]}\end{array}$ & $\begin{array}{l}\text { Polymer } \\
\text { hollow fiber } \\
\text { membrane } \\
\text { contactor }\end{array}$ & $\begin{array}{l}\text { Cross } \\
\text { flow }\end{array}$ & Indirect & Numerical & $\mathrm{LiCl}$ & $\begin{array}{l}\text { A free surface model with defined } \\
\text { boundary conditions was developed } \\
\text { to evaluate hollow fiber membrane } \\
\text { module. However, the experimental } \\
\text { results were not available. }\end{array}$ \\
\hline $\begin{array}{l}\text { Zhang et al. } \\
{[39,40]}\end{array}$ & $\begin{array}{ll}\text { Two } r & \text { stage } \\
\text { hollow fiber } \\
\text { membrane } \\
\text { contactor }\end{array}$ & $\begin{array}{l}\text { Counter } \\
\text { flow }\end{array}$ & Indirect & Numerical & $\mathrm{LiCl}$ & $\begin{array}{l}\text { A heat pump powered two-stage } \\
\text { dehumidification system using } \\
\text { membrane as the dehumidifier was } \\
\text { numerically analyzed with } \\
\text { performance improvement of } 20 \% \\
\text { against single stage system. } \\
\text { However, the model was not } \\
\text { validated against experimental } \\
\text { results. }\end{array}$ \\
\hline $\begin{array}{l}\text { The present } \\
\text { work }\end{array}$ & \begin{tabular}{|l|} 
Polymer \\
hollow fiber \\
integrated \\
dehumidifier \\
(PHFD)
\end{tabular} & $\begin{array}{l}\text { Cross } \\
\text { flow }\end{array}$ & Indirect & Both & \begin{tabular}{|l|}
$\mathrm{KCOOH}$ \\
(Potassium \\
formate)
\end{tabular} & $\begin{array}{l}\text { Model validation have been carried } \\
\text { out in three parts: validation against } \\
\text { 1) laboratory obtained testing results, } \\
\text { 2) previous established analytical } \\
\text { results and 3) other published } \\
\text { simulation results from the literature. } \\
\text { Based on this, a set of PHFD } \\
\text { performance tables and charts have } \\
\text { been developed, which will be easily } \\
\text { applied by designers in the practical } \\
\text { cases. }\end{array}$ \\
\hline
\end{tabular}

\section{The mathematical model}

\subsection{Heat/mass transfer coefficients for air side and solution side}

As shown in Fig. 1, the PHFD module is designed as the interface between air flow and solution flow, which respectively occur outside and inside of the hollow fibers. The heat and mass transfer process of the PHFD model can be considered as three mechanisms: the sensible and latent heat transfer between the air side and the solution side, and the moisture transfer from the air side into the solution side. Therefore, the heat and mass transfer coefficients for both the air side and solution side can be calculated using the modified 

following sections.

158

159

160

161

162

163

164

165

166

167

168

169

$170 \frac{h d_{i}}{\lambda}$

171

172

173

174

$175=\frac{k \mathrm{~d}_{i}}{\psi_{w}}$

176

177 $178 \quad$ Number $\left(\mathrm{Gz}=\frac{u d_{i}}{\psi_{w} L}\right)$ over 25.

$179 \mathrm{Sh}_{\text {sol }}$

$180=1.62\left(\frac{d_{i}^{2} u_{s o l, i}^{2}}{L \psi_{w}}\right)^{\frac{1}{3}}$ 100:

$$
\mathrm{Nu}_{\text {sol }}
$$

$\mathrm{Nu}_{\text {sol }}=$ as:

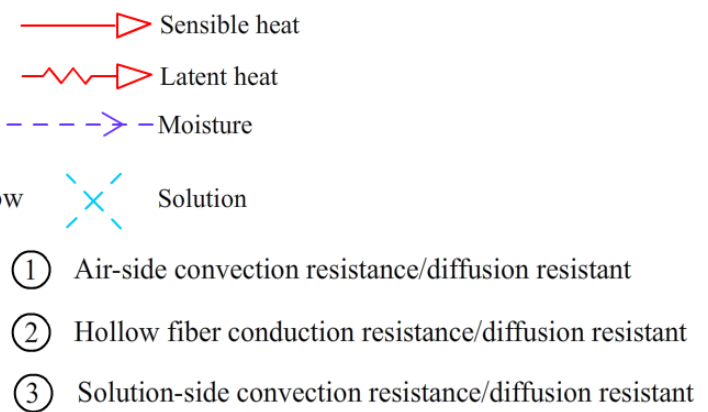

(3) Solution-side convection resistance/diffusion resistant

Fig. 1 Heat and mass transfer scheme of the PHFD model

\subsubsection{Solution-side heat and mass transfer coefficient}

The heat transfer coefficient $h\left(\mathrm{~W} / \mathrm{m}^{2} \mathrm{~K}\right)$ at the solution side can be determined by the Nusselt number, which can be calculated by the following Gnielinski correlation $[45,46]$ with $\frac{R e P r d_{i}}{L}<$

$$
=\mathrm{Nu}_{l i m}+\frac{0.085\left[\frac{R e P r d_{i}}{L}\right]}{1+0.047\left[\frac{\operatorname{RePrd} d_{i}}{L}\right]^{0.67}}\left(\frac{v_{b}}{v_{s}}\right)^{0.14}
$$

Where the subscripts ' $b$ ' and ' $s$ ' refer to bulk and surface respectively. For the laminar flow inside the hollow fiber, the lower limit value of the Nusselt number $\left(\mathrm{Nu}_{\text {lim }}\right)$ is 3.658[45]. The relationship between Nusselt number and the heat transfer coefficient can be expressed as:

Where $d_{i}(\mathrm{~m})$ is the fiber inside diameter, and $\lambda(\mathrm{W} / \mathrm{mK})$ is the thermal conductivity.

The mass transfer coefficient $k(\mathrm{~m} / \mathrm{s})$ is related to the Sherwood number, which can be defined

The Sherwood number can be derived from the Leveque equation[47, 48] which is suitable for tube laminar flows $(\operatorname{Re}<2300)$ with small fiber inside diameter $\left(d_{i}<1.5 \mathrm{~mm}\right)$ and Graetz 
Where $\psi_{w}\left(\mathrm{~m}^{2} / \mathrm{s}\right)$ represents water diffusivity in the solution inside the hollow fiber, $d_{i}(\mathrm{~m})$ is the fiber inside diameter, $u_{s o l, i}(\mathrm{~m} / \mathrm{s})$ is the solution inlet velocity.

\subsubsection{Air-side heat and mass transfer coefficient}

According to [49], when air flow crosses a bundle of tubes with $\operatorname{Re}_{D, \max }$ in the range of 2000 to 40000 and $\operatorname{Pr}$ over than 0.7 , the heat transfer coefficient at the air side is given by:

$$
\mathrm{Nu}_{\text {air }}
$$

$$
=1.13 \mathrm{C}_{1} \operatorname{Re}_{D, \max }^{m} \operatorname{Pr}^{\frac{1}{3}}
$$

Where $\mathrm{C}_{1}$ and $\mathrm{m}$ can be obtained from [49], and $\mathrm{Re}_{D, \max }$ can be calculated by:

$\operatorname{Re}_{D, \max }=\frac{d_{h, a i r} u_{\max }}{v}$

Where $u_{\max }(\mathrm{m} / \mathrm{s})$ is the maximum air velocity passing through the air channel, which can be calculated by:

$u_{\text {max }}=\frac{u_{\text {air }, i} d_{h, a i r}}{d_{h, \text { air }}-d_{o}}$

$d_{h, a i r}(\mathrm{~m})$ is the equivalent hydraulic diameter of the air channel, which can be calculated as:

$\mathrm{d}_{h, \text { air }}=\frac{(1-\varphi) d_{c}^{2}}{n_{f} d_{o}+d_{c}}$

Where $d_{o}(\mathrm{~m})$ is the fiber outside diameter, $d_{c}(\mathrm{~m})$ is the module cross section diameter. $n_{f}$ is the number of fibers included in the module, and $\varphi$ is the packing fraction of the module, i.e. the ratio of the total fiber surface area to the PHFD module surface are, $\varphi$

$=\frac{n_{f} \pi \mathrm{d}_{o}^{2}}{\pi \mathrm{d}_{c}^{2}}$

As indicated by Zhang et al. [47], for the proposed PHFD configuration, at lower inlet air velocity, the air flow could be considered as laminar flow with the air side mass transfer correlation shown in the following equation:

$$
\begin{gathered}
\mathrm{Sh}_{\text {air }}=\left(14.06 \varphi^{4}-29.21 \varphi^{3}+22.59 \varphi^{2}-7.71 \varphi\right. \\
+1.03) R e^{0.33} S c^{0.33} \tau_{k}
\end{gathered}
$$

Where air side Schmidt number can be calculated as:

$\mathrm{Sc}_{\text {air }}$

$=\frac{\mu_{\text {air }}}{\rho_{\text {air }} \psi_{\text {air }}}$

Where $\mu_{\text {air }}(\mathrm{Pa} \bullet \mathrm{s})$ is the air dynamic viscosity, $\rho_{\text {air }}\left(\mathrm{kg} / \mathrm{m}^{3}\right)$ is the air density, and $\psi_{\text {air }}\left(\mathrm{m}^{2} / \mathrm{s}\right)$ is the moisture diffusivity in air and $\tau_{k}=0.882 \tau_{f}-0.535$ where $\tau_{f}$ is the fractal dimension of the fiber packing. For the irregular and regular packing, the value of $\tau_{f}$ is 1 and 2, respectively, and the general value is 1.6 to $1.9[48]$.

\subsubsection{Overall heat and mass transfer coefficients}

The overall heat and mass transfer resistance should take into account the air-side resistance, solution-side resistance and hollow fiber resistance. The calculation equations were described in detail by Zhang et al.[48]. The overall heat transfer coefficient $\left(\mathrm{h}_{o v}\right)$ and the overall mass 
transfer coefficient $\left(\mathrm{k}_{o v}\right)$ are estimated as the sums of the individual resistances, as shown in the following equations:

$$
\begin{aligned}
\mathrm{h}_{o v}=\left(\frac{1}{h_{i}}\left(\frac{d_{o}}{d_{i}}\right)\right. & +\frac{\delta}{\lambda_{m}}\left(\frac{d_{o}}{\bar{d}}\right) \\
& \left.+\frac{1}{h_{o}}\right)^{-1} \\
\mathrm{k}_{o v}=\left(\frac{1}{k_{i}}\left(\frac{d_{o}}{d_{i}}\right)\right. & +\frac{\delta}{\psi_{m}}\left(\frac{d_{o}}{\bar{d}}\right) \\
& \left.+\frac{1}{k_{o}}\right)^{-1}
\end{aligned}
$$

where $\bar{d}(\mathrm{~m})$ is the average value of the fibers diameter, $\delta(\mathrm{m})$ is the thickness of the hollow fiber, $d_{o}(\mathrm{~m})$ and $d_{i}(\mathrm{~m})$ is the hollow fiber outside and inside diameter respectively. $\psi_{m}\left(\mathrm{~m}^{2} / \mathrm{s}\right)$ is the effective mass diffusivity of the hollow fiber and $\lambda_{m}(\mathrm{~W} / \mathrm{mK})$ is the effective thermal conductivity.

\subsection{Heat and mass conservation equations}

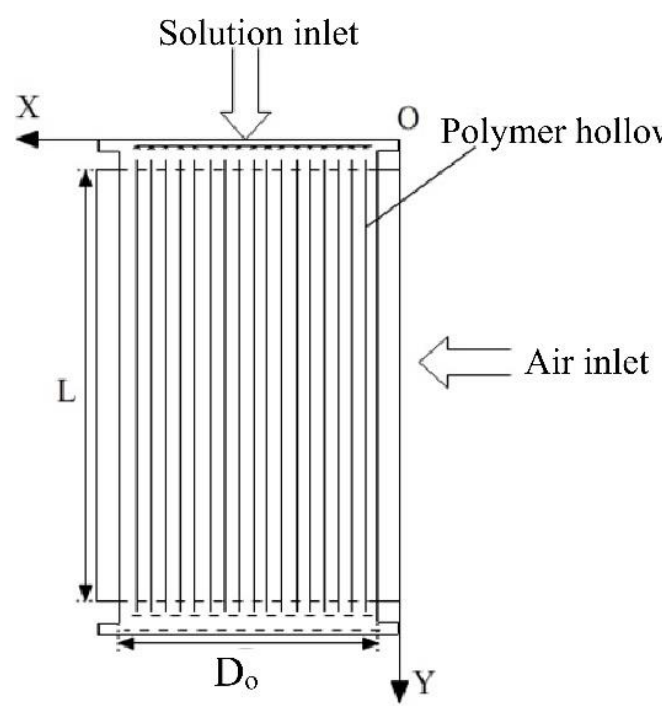

(A)

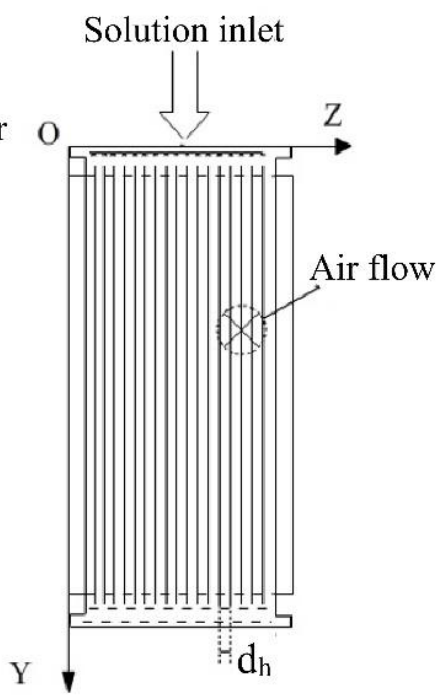

(B)

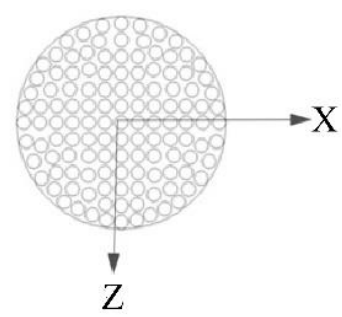

(C)

Fig. 2 The proposed polymer hollow fiber dehumidifier: $(A)$ and (B) front view (C) section view

The proposed hollow fiber integrated crossflow desiccant dehumidifier is illustrated in Fig. 2. To simplify the numerical model, a series of basic assumptions were made:

(1) According to the numerical simulation presented by Ge et al.[28], when the fibers are arranged in staggered pattern with solution side Re number less than 2000 , the solution side flow can be consider as fully developed and laminar.

(2) The physical properties of the air, solution, and the polymer hollow fiber, such as the specific heat, heat conductivity, etc. are constant.

(3) The model is based on a two-dimensional cross-flow, with each fluid flowing in a single direction.

(4) The axial water molecular diffusion, and the conduction of heat in the hollow fibers are 
ignored, since the Peclet number in both channels is larger than $20[50,51]$.

(5) Moisture condensates only in the liquid side, and the latent heat arising from phase changes is also released only in the liquid side.

(6) All the fibers inside the PHFD module are assumed to be uniformly distributed, therefore, the solution will be distributed uniformly through each single fibers.

\subsubsection{Air-side and solution-side governing equations}

The solution-side heat and mass conservation equations are given as $\left(\frac{\dot{m}_{s o l}}{n_{e q} d_{i}} \cdot \frac{\partial T_{s o l}}{\partial y} \cdot C_{p, \text { sol }}\right)$

$$
\begin{aligned}
&=\mathrm{h}_{o v}\left(T_{a i r}-T_{s o l}\right)+h_{f g} \cdot \mathrm{k}_{o v} \cdot \rho_{a}\left(\omega_{a i r}-\omega_{s o l}\right) \\
& \frac{\dot{m}_{s o l}}{n_{e q} d_{i}} \cdot \frac{\partial X_{s o l}}{\partial y}=\mathrm{k}_{o v} \cdot \rho_{a} \cdot\left(\omega_{\text {air }}-\omega_{s o l}\right)
\end{aligned}
$$

where $\dot{m}_{\text {sol }}(\mathrm{kg} / \mathrm{s})$ is the solution mass flow rate, $T_{\text {sol }}\left({ }^{\circ} \mathrm{C}\right)$ and $T_{\text {air }}\left({ }^{\circ} \mathrm{C}\right)$ are the solution temperature and air inlet temperature respectively, $\omega_{\text {air }}\left(\mathrm{kg}\right.$ moisture/ $\mathrm{kg}$ air) and $\omega_{\text {sol }}(\mathrm{kg}$ $\mathrm{KCOOH} / \mathrm{kg}$ solution) are the air humidity ratio and desiccant solution mass fraction, and $n_{e q}$ is the equivalent number of fibers, which can be calculated as:

$n_{e q}=\frac{A_{t o t}}{d_{c} L}$

Where $d_{c}(m)$ is the dehumidifier module cross section diameter, $L(m)$ is the height of the hollow fiber model, $A_{t o t}\left(m^{2}\right)$ is the total heat exchange area, which can be calculated as :

$A_{\text {tot }}=\mathrm{n} \pi d_{o} L$

The air-side governing equations are given as:

$\frac{\dot{m}_{\text {air }}}{n_{e q} d_{h}} \cdot c_{p, \text { air }} \cdot \frac{\partial T_{\text {air }}}{\partial x}$

$=h_{o v}\left(T_{\text {sol }}-T_{\text {air }}\right)$
$\frac{\dot{m}_{\text {air }}}{n_{e q} d_{h}} \cdot \frac{\partial \omega_{\text {air }}}{\partial x}+k_{o v}\left(\omega_{\text {air }}-\omega_{\text {sol }}\right)=0$

where the $\dot{m}_{\text {air }}(\mathrm{kg} / \mathrm{s})$ is the air flow rate, $c_{p, \text { air }}(\mathrm{J} / \mathrm{kg} \mathrm{K})$ is the air specific heat capacity.

\subsubsection{Normalized equations}

A range of dimensionless parameters can also be used:

The dimensionless temperature:

$T^{*}=\frac{T-T_{\text {air }, i}}{T_{\text {sol }, i}-T_{\text {air }, i}}$

The dimensionless humidity ratio:

$\omega^{*}=\frac{\omega-\omega_{a i r, i}}{\omega_{s o l, i}-\omega_{a i r, i}}$

The dimensionless coordinates:

$x^{*}=\frac{x}{d_{c}}$

$y^{*}=\frac{y}{L}$ 
The dimensionless heat capacity ratios including sensible heat capacity ratio $m_{\text {sen }}$ and latent heat capacity ratio $m_{\text {lat }}$ are defined below:

$m_{\text {sen }}=\frac{\dot{m}_{\text {air }} C_{p, \text { air }}}{\dot{m}_{\text {sol }} C_{p, \text { sol }}}$

$m_{\text {lat }}=\frac{\dot{m}_{a i r} h_{f g}\left(\omega_{s o l, i}-\omega_{a i r, i}\right)}{\dot{m}_{s o l} C_{p, s o l}\left(T_{s o l, i}-T_{a i r, i}\right)}$

The number of transfer unit is defined by:

$N T U=\frac{h_{o v} A_{t o t}}{\left(\dot{m} c_{p}\right)_{\text {air }}}$

And the number of mass transfer unit is defined by:

$$
N T U_{m}=\frac{\rho_{\text {air }} k_{o v} A_{t o t}}{\dot{m}_{\text {air }}}
$$

The normalized formulae for the heat and mass conservation on the air side are:

$$
\frac{\partial T_{\text {air }}{ }^{*}}{\partial x^{*}}=\operatorname{NTU}\left(T_{\text {sol }}{ }^{*}-T_{\text {air }}{ }^{*}\right)
$$

$\frac{\partial \omega_{a i r}^{*}}{\partial x^{*}}=N T U_{m}\left(\omega_{s o l}^{*}-\omega_{a i r}^{*}\right)$

Similarly, the normalized formulae for the heat and mass conservation on the solution side are:

$\frac{\partial T_{\text {sol }}{ }^{*}}{\partial y^{*}}=m_{\text {sen }} N T U\left(T_{\text {air }}{ }^{*}-T_{\text {sol }}{ }^{*}\right)+m_{\text {lat }} N T U_{m}\left(\omega_{\text {air }}{ }^{*}-\omega_{\text {sol }}{ }^{*}\right)$

$\frac{\partial \omega_{s o l}^{*}}{\partial y^{*}}=\mathrm{M} \frac{\partial T_{s o l}^{*}}{\partial y^{*}}$

where $\mathrm{M}$ is related to the dimensionless solution humidity ratio and the dimensionless solution temperature:

$\mathrm{M}=E_{\mathrm{T}} \frac{T_{s o l, i}-T_{a i r, i}}{\omega_{s o l, i}-\omega_{\text {air }, i}}$

where $E_{\mathrm{T}}$ is related to the solution humidity ratio and the solution temperature, which is defined as:

$\mathrm{E}_{T}=\left.\frac{\partial \omega_{\text {sol }}}{\partial T_{\text {sol }}}\right|_{\bar{X}_{\text {sol }}}$

with

$\omega_{\text {sol }}=0.622 \frac{P_{\text {sol }}\left(X_{\text {sol }}, T_{\text {sol }}\right)}{P_{\text {atm }}-P_{\text {sol }}\left(X_{\text {sol }}, T_{\text {sol }}\right)}$

where $P_{a t m}(P a)$ is the atmospheric pressure; $P_{\text {sol }}(P a)$ is the solution's vapor pressure at a particular concentration and temperature, which can be obtained by;

$\mathrm{P}_{\text {sol }}=X_{\text {sol }} \cdot \exp ^{\gamma} \cdot \exp ^{P_{\mathrm{H}_{2} \mathrm{O}}}$ where the parameters $X_{s o l}, \gamma, P_{\mathrm{H}_{2} \mathrm{O}}$, are parameters related to desiccant solution and can be found in[52]. The concentration of the desiccant solution can be calculated via the correlation developed by Melinder [53], which relies on the temperature and density of the solution, as shown below:

$$
X_{\text {sol }}=-253.148+0.04438563996 T_{\text {sol }}+0.000162666247 T_{\text {sol }}^{2}+0.331709855 T_{\text {sol }}-
$$
$0.000079370267 \rho_{\text {sol }}$ 
307 The solution side boundary conditions are:

308

309

310

311

312 $T_{\text {sol }}{ }^{*}=1$, at $y^{*}=0$ $\omega_{\text {sol }}{ }^{*}=1$, at $y^{*}=0$

The air side boundary conditions are:

$T_{\text {air }}{ }^{*}=0$, at $x^{*}=0$

$\omega_{\text {air }}^{*}=0$, at $x^{*}=0$

\subsection{Performance indices}

Effectiveness is a key performance indicator of the dehumidifier. The sensible effectiveness $\varepsilon_{\text {sen }}$, latent effectiveness $\varepsilon_{\text {lat }}$, and total effectiveness $\varepsilon_{\text {tot }}$ were used to evaluate the proposed model. The sensible effectiveness $\varepsilon_{\text {sen }}$ is determined as the ratio of the air-temperature difference between the area-averaged outlet and the inlet, to the difference between the inlet solution temperature and the inlet air temperature (Eq. 38). The latent effectiveness $\varepsilon_{\text {lat }}$ is the ratio of the area-averaged inlet and outlet air humidity difference to the humidity difference between the solution and the air at the inlet (Eq. 39);

$\varepsilon_{\text {sen }}=\frac{T_{\text {air }, o}-T_{\text {air }, i}}{T_{\text {sol, },}-T_{\text {air }, i}}$

$\varepsilon_{\text {lat }}=\frac{\omega_{\text {air }, o}-\omega_{\text {air }, i}}{\omega_{\text {sol }, i}-\omega_{\text {air }, i}}$

The total effectiveness $\varepsilon_{t o t}$ is the ratio between the maximum and the actual energy transfer rates, which could be expressed as in (Eq. 40);

$\varepsilon_{t o l}=\frac{\varepsilon_{s e n}+h_{f g} \frac{\left(\omega_{a i r, i}-\omega_{s o l, i}\right)}{\left(T_{a i r, i}-T_{s o l, i}\right)} \varepsilon_{l a t}}{1+h_{f g} \frac{\left(\omega_{a i r, i}-\omega_{s o l, i}\right)}{\left(T_{a i r, i}-T_{s o l, i}\right)}}$

The moisture removal rate $M(\mathrm{~kg} / \mathrm{s})$ is also a very important performance indicator of the liquid desiccant PHFD, and can be determined as:

$M=\dot{m_{a}}\left(\omega_{\text {air }, i}-\omega_{\text {air }, o}\right)$

\subsection{Simulations}

Eqs. (28) to (31) are the governing partial difference equations for the heat and mass transfer in the proposed model. They are two-dimensional and two-variable partial differential equations. A series of finite-differences iterations are performed in Matlab until the results converged. A grid independence test was performed in order to optimize the grids. It was found that grids of $60 \times 60$ were sufficient for this study, as the difference of the results is less than $1 \%$ compared to $60 \times 120$ grids. The process followed in this study is shown in the flowchart of Fig.3. 


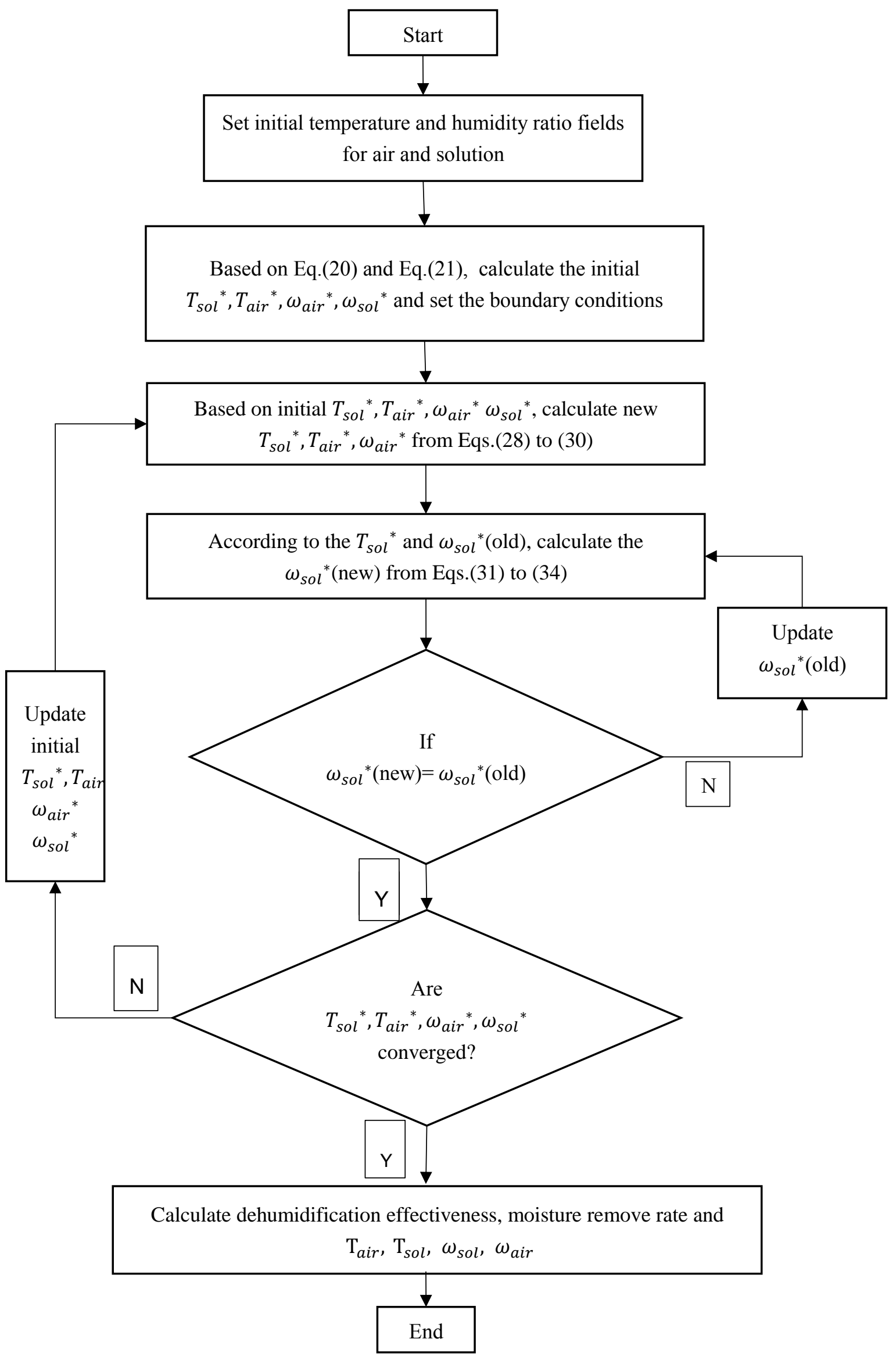

Fig.3. Flow chart for the simulation procedure 
341 The experimental dehumidifier was assembled in the Marmot laboratory, University of 342 Nottingham, UK. The schematic diagram and the experimental set up can be found in Fig.4 (A) 343 and (B), respectively. The system includes the following major components: the polymer 344 hollow-fiber dehumidifier, the air channel, a fan, two circulation pumps, two solution tanks and 345 a water filter. The major component is the dehumidifier module with module cross section 346 diameter of $0.2 \mathrm{~m}$ and length of $0.6 \mathrm{~m}$. 5500 porous hollow fibers were combined as a bundle 347 and attached on either end to a plastic disc by means of adhesive sealant. The polymer hollow348 fiber dehumidifier was further integrated in a transparent plastic box to allow interactions with 349 the incoming air. The aluminum air channel was attached to a centrifugal air fan with variable 350 frequency, connected in turn to the environmental chamber with supply of humid and hot air of 351 temperatures between $25^{\circ} \mathrm{C}$ and $40^{\circ} \mathrm{C}$, and relative humidity of $0-75 \%$. Two plastic tanks of an 352 eight-liter capacity carried the strong and weak solutions of the liquid potassium. Located at 353 the entrance of the PHFD, the water filter would help to eliminate any small particles entering 354 into the liquid desiccant solution. A ball valve and a flow-meter were fixed at the entrance to 355 the polymer hollow fiber module to control the solution flow rate inside the fibers. The physical 356 and geometrical properties of the PHFD are listed in Table 2.

357 The experiments were conducted as follows. The intake air from the environmental chamber 358 was directed inside the dehumidifier, once the environmental chamber had reached the required temperature and relative humidity. The strong $\mathrm{KCOOH}$ solution was pumped from the strong solution tank by a centrifugal pump $(25 \mathrm{~W})$, to the desiccant solution inlet of the hollow fiber module, where it was sprayed from the top of the PHFD and was left to trickle down into the module. After being exposed to the inlet air, the dilute solution was collected into the relevant weak solution tank. It was then pumped into the regenerator, constructed as an aluminum-plate heat exchanger. Hot water $\left(\sim 80^{\circ} \mathrm{C}\right)$ was fed to the regenerator by a $3 \mathrm{~kW}$ electrical boiler for the purpose of desiccant regeneration. Once the solution concentration achieved its desired ratio, it was returned to the strong-solution reservoir by a $25 \mathrm{~W}$ single-phase centrifugal pump. 


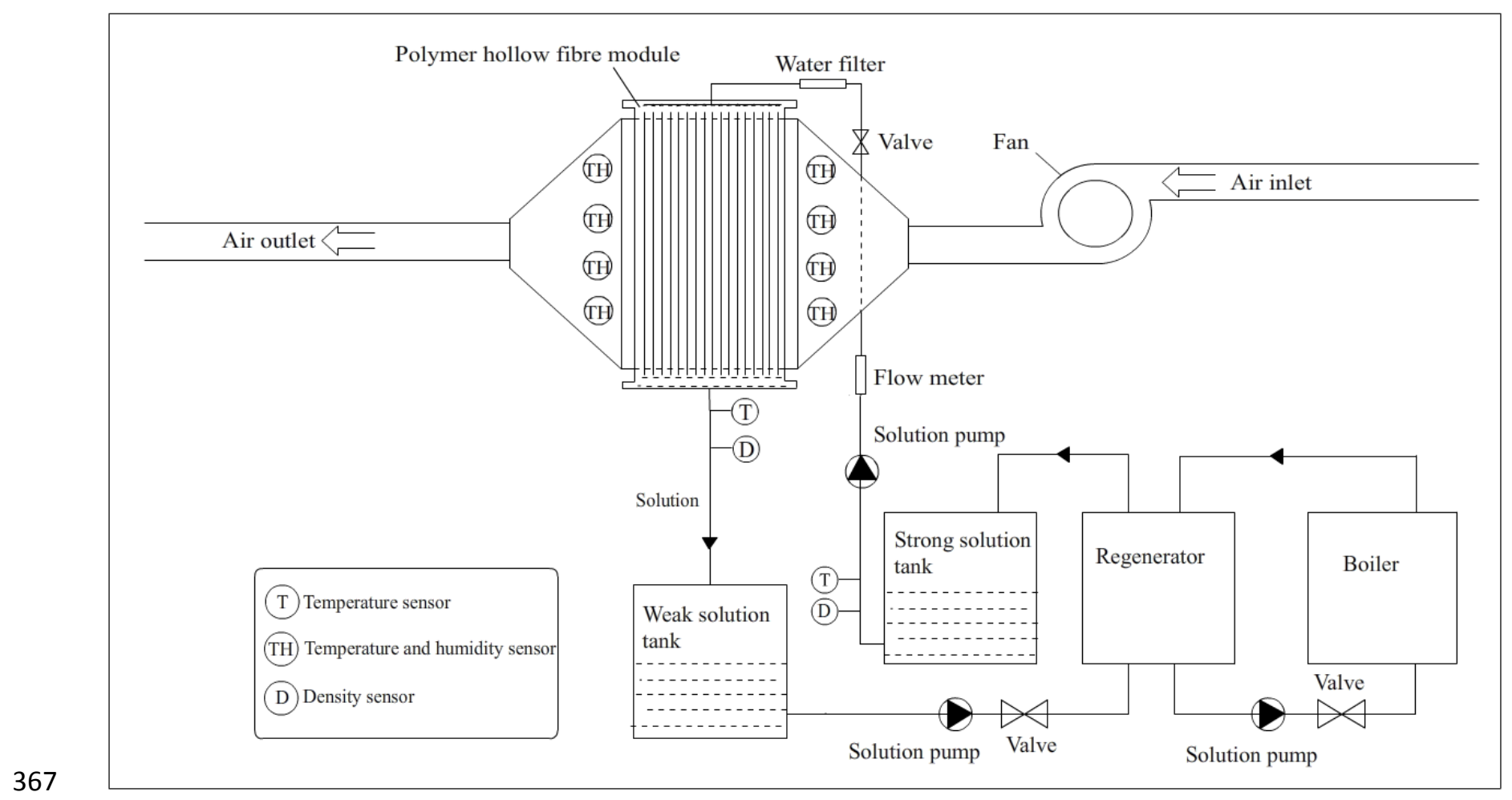

(A)

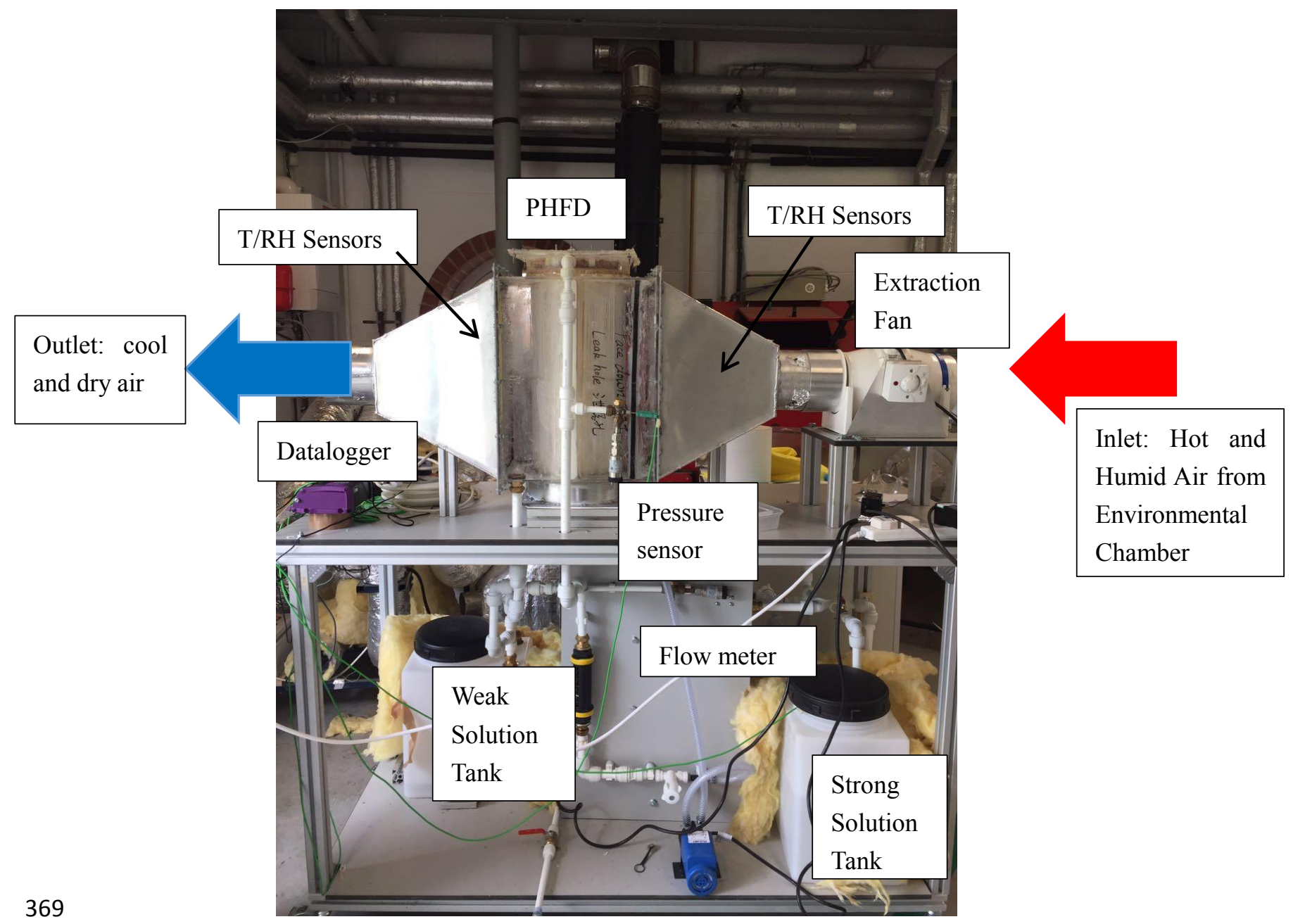

(B) 
Fig. 4 Schematic diagram (A) and experimental set up (B) of the hollow fiber integrated liquid desiccant dehumidifier

Air temperature and humidity were measured by four dedicated monitoring devices (EK-H4, Sensirion, UK), which were placed by the inlet and the outlet of the air channel. The solution temperature was measured using K-type thermocouples. The air velocities in the air channel of the hollow fibre module were measured by a Testo anemometer. Its probe was distributed over several points around the outlet and inlet of the air tunnel. The dynamic pressure of the desiccant solution was mesured by the Pressure transducers (Ge UNIK 5000). Finally, a DT500 data logger collected all the data from the above sensors. Detailed information about the measure sensors, for example, the measurement accuracy and measurement range are shown in Table 3. Uncertainty analysis of the experimental results was conducted following Moffat's method[54], and is shown in Fig. 5-12.

Table 2. Physical and transport properties of the polymer hollow-fiber dehumidifier

\begin{tabular}{|c|c|c|c|}
\hline Property & Parameter & Values & Unit \\
\hline Dehumidifier cross section diameter & $d_{c}$ & 0.20 & $\mathrm{~m}$ \\
\hline Dehumidifier height & $\mathrm{L}$ & 0.6 & $\mathrm{~m}$ \\
\hline Number of fibers inserted & $n_{f}$ & 5500 & \\
\hline Fiber outside diameter & $d_{o}$ & 1.6 & $\mathrm{~mm}$ \\
\hline Fiber inside diameter & $d_{i}$ & 1.4 & $\mathrm{~mm}$ \\
\hline Pore size (nominal) & & 0.2 & $\mu \mathrm{m}$ \\
\hline Fibre porosity & & 0.6 & \\
\hline Packing density & & 832 & $\mathrm{~m}^{2} / \mathrm{m}^{3}$ \\
\hline Packing fraction & $\varphi$ & 0.32 & \\
\hline Fibre thermal conductivity & $\lambda$ & 0.17 & $\mathrm{~W} / \mathrm{mK}$ \\
\hline Solution concentration & $X$ & $57-67$ & $\%$ \\
\hline Inlet air velocity & $u_{\text {air }}$ & $0.65-4.5$ & $\mathrm{~m} / \mathrm{s}$ \\
\hline Solution mass flow rate & $\dot{m}_{\text {sol }}$ & $0.028-0.125$ & $\mathrm{~kg} / \mathrm{s}$ \\
\hline Inlet air temperature & $T_{\text {air }}$ & $35-40$ & ${ }^{\circ} \mathrm{C}$ \\
\hline Inlet air relative humidity & $\omega_{\text {air }}$ & $55-80$ & $\%$ \\
\hline Specific heat of solution & $C_{\text {sol }}$ & 3.1 & $\mathrm{~kJ} / \mathrm{kg} \mathrm{K}$ \\
\hline Dynamic viscosity of solution & $\mu_{\text {sol }}$ & $5.1 \times 10^{-3}$ & $\mathrm{~Pa} \cdot \mathrm{s}$ \\
\hline Heat of evaporation & $h_{f g}$ & 2501 & $\mathrm{~kJ} / \mathrm{kg}$ \\
\hline Moisture diffusivity in air & $\psi_{\text {air }}$ & $2.82 \times 10^{-5}$ & $\mathrm{~m}^{2} / \mathrm{s}$ \\
\hline Effective mass diffusivity of the hollow fiber & $\psi_{m}$ & $1.2 \times 10^{-5}$ & $\mathrm{~m}^{2} / \mathrm{s}$ \\
\hline Water diffusivity in solution & $\psi_{w}$ & $0.3 \times 10^{-2}$ & $\mathrm{~m}^{2} / \mathrm{s}$ \\
\hline Number of heat transfer unit & $N T U$ & $0.46-4.4$ & \\
\hline Number of mass transfer unit & $N T U_{m}$ & $0.28-2.8$ & \\
\hline
\end{tabular}


Table 3 Measurement devices and their accuracy

\begin{tabular}{llll}
\hline \multicolumn{1}{c}{ Instrumentation } & \multicolumn{1}{c}{ Measured parameter } & Measurement range & accuracy \\
\hline $\begin{array}{l}\text { Humidity and temperature } \\
\text { sensors }\end{array}$ & Air (relative) humidity & $0-90 \% \mathrm{RH}$ & $\pm 2 \%$ \\
Humidity and temperature & Air temperature & $-40-125^{\circ} \mathrm{C}$ & $\pm 0.3 \%$ \\
sensors & & & \\
Testo thermo-anemometer & Air velocity & $0-10 \mathrm{~m} / \mathrm{s}$ & $\pm 5 \%$ \\
K-type thermocouple & Desiccant solution temperature & $0-1100{ }^{\circ} \mathrm{C}$ & $\pm 0.75 \%$ \\
$\begin{array}{l}\text { Datalogger DT500 } \\
\text { Branna hydrometer 200 }\end{array}$ & Data Acquisition & & $\pm 0.15 \%$ \\
series & Solution density & $1.0-1.6 \mathrm{~g} / \mathrm{m}^{3}$ & $\pm 2 \%$ \\
Parker liquid flow indicator & Desiccant solution flow rate & $0-5 \mathrm{litre} / \mathrm{min}$ & $\pm 5 \%$ \\
\hline
\end{tabular}

\section{Results and discussion}

\subsection{Model validation}

\subsubsection{Experimental validation}

The simulation results were validated against experimental results using 5 groups of experimentally obtained data. According to[49], since the ratio of hydraulic diameter of the air channel to the fiber outside diameter is equal to 2, the two parameters $C_{1}$ and $\mathrm{m}$ in Eq. (5) is chosen as 0.229 and 0.632 , respectively. Under the various operating NTU and $\mathrm{Cr}^{*}$ conditions, the calculated and experimentally obtained outlet air temperature, specific humidity, outlet solution temperature, sensible effectiveness and latent effectiveness have been listed in Table 4 and Table 6. It is obvious that the proposed model matches well with the experimental results for both sensible effectiveness and latent effectiveness, with discrepancy in the range of 3.1$9.3 \%$ for sensible effectiveness and $2.5-8.9 \%$ for latent effectiveness. Therefore, this model in general can successfully predict the heat and mass transfer process in the PHFD.

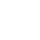

(1)




\begin{tabular}{|c|c|c|c|c|c|c|c|c|c|}
\hline Operating & & & & & Parameters & & & & \\
\hline NTU & $\mathrm{T}_{\text {air,o }}(\exp )$ & $\mathrm{T}_{\text {air,o }}($ num) & Error(\%) & $\mathrm{T}_{\mathrm{sol}, \mathrm{o}}(\exp )$ & $\mathrm{T}_{\mathrm{sol}, \mathrm{o}}(\mathrm{num})$ & Error(\%) & $\varepsilon_{\mathrm{sen}}(\exp )$ & $\varepsilon_{\text {sen }}($ num $)$ & Error( $(\%)$ \\
\hline 0.4684 & 33.07 & 33.00 & 0.2 & 29.75 & 29.85 & 0.3 & 0.351 & 0.363 & 3.3 \\
\hline 0.6012 & 32.74 & 32.59 & 0.5 & 29.86 & 29.93 & 0.2 & 0.4113 & 0.437 & 4.6 \\
\hline 1.2764 & 31.19 & 31.32 & 0.4 & 30.27 & 30.21 & 0.2 & 0.693 & 0.668 & 3.1 \\
\hline 3.045 & 30.29 & 30.21 & 0.3 & 30.59 & 30.67 & 0.3 & 0.856 & 0.927 & 7.6 \\
\hline 4.4126 & 30.15 & 30.07 & 0.3 & 30.89 & 30.97 & 0.2 & 0.882 & 0.973 & 9.3 \\
\hline
\end{tabular}
conditions
Table 5 Comparisons between numerically obtained and experimentally obtained latent effectiveness under various $\mathrm{NTU}_{\mathrm{m}}\left(\mathrm{m}^{*}=0.75\right)$

\begin{tabular}{|c|c|c|c|c|c|c|c|c|c|}
\hline $\mathrm{NTU}_{\mathrm{m}}$ & $\omega_{\text {sol,o }}(\exp )$ & $\omega_{\text {sol,o }}($ num $)$ & Error $(\%)$ & $\omega_{\text {air,o }}(\exp )$ & $\omega_{\text {air,o }}($ num $)$ & Error(\%) & $\varepsilon_{\mathrm{lat}}(\exp )$ & $\varepsilon_{\text {lat }}($ num $)$ & Error $(\%)$ \\
\hline 0.2803 & 0.0117 & 0.0118 & 0.3 & 0.0192 & 0.0190 & 1.0 & 0.191 & 0.196 & 2.5 \\
\hline 0.8318 & 0.0122 & 0.0125 & 2.4 & 0.0164 & 0.0160 & 2.4 & 0.478 & 0.514 & 7.0 \\
\hline 1.3232 & 0.0124 & 0.0129 & 4.0 & 0.0149 & 0.0144 & 4.0 & 0.613 & 0.664 & 7.6 \\
\hline 1.8631 & 0.0126 & 0.0132 & 4.8 & 0.0140 & 0.0135 & 3.5 & 0.702 & 0.748 & 6.5 \\
\hline 2.8631 & 0.0127 & 0.0134 & 5.5 & 0.0135 & 0.0127 & 5.9 & 0.749 & 0.822 & 8.9 \\
\hline
\end{tabular}

412 Analytical solutions for an enthalpy exchanger considering a membrane core have been 413 reported in various works $[55,56]$. According to these, the sensible effectiveness and latent 
effectiveness of cross flow is given by the NTU- $\varepsilon$ method. Those parameters are functions of four dimensionless parameters; the former are NTU and $\mathrm{Cr}^{*}$ and the latter are $\mathrm{NTU}_{\mathrm{m}}$ and

$416 \mathrm{~m}^{*}[36]$ :

$417 \varepsilon_{\text {sen }}$

$418=1-\exp \left[\frac{\exp \left(-N T U^{0.78} C_{r}^{*}\right)-1}{N T U^{-0.22} C_{r}{ }^{-1}}\right]$

419

$\varepsilon_{\text {lat }}=1-\exp \left\{\frac{N T U_{m}{ }^{0.22}}{m^{*-1}}\left[\exp \left(-m^{*} N T U_{m}{ }^{0.78}\right)\right.\right.$

420

$$
-1]\}
$$

421 The results of the analytical solutions in Fig. 5 show a trend consistent with the numerical modelling results. As it can be seen in Fig. 5, a good agreement between numerical and experimental results occurs when the inlet air flow rate is less than $0.02 \mathrm{~kg} / \mathrm{s}$. As the value of NTU and $\mathrm{NTU}_{\mathrm{m}}$ increases, the two curves start to deviate. This is because the higher the NTU and $\mathrm{NTU}_{\mathrm{m}}$, the lower the air velocity and solution mass flow rate. With the 5500 hollow fibers imbedded in one module, the inner parts of the hollow fibers will have less opportunity to be exposed to the incoming air, leading to a decrease in heat transfer performance.

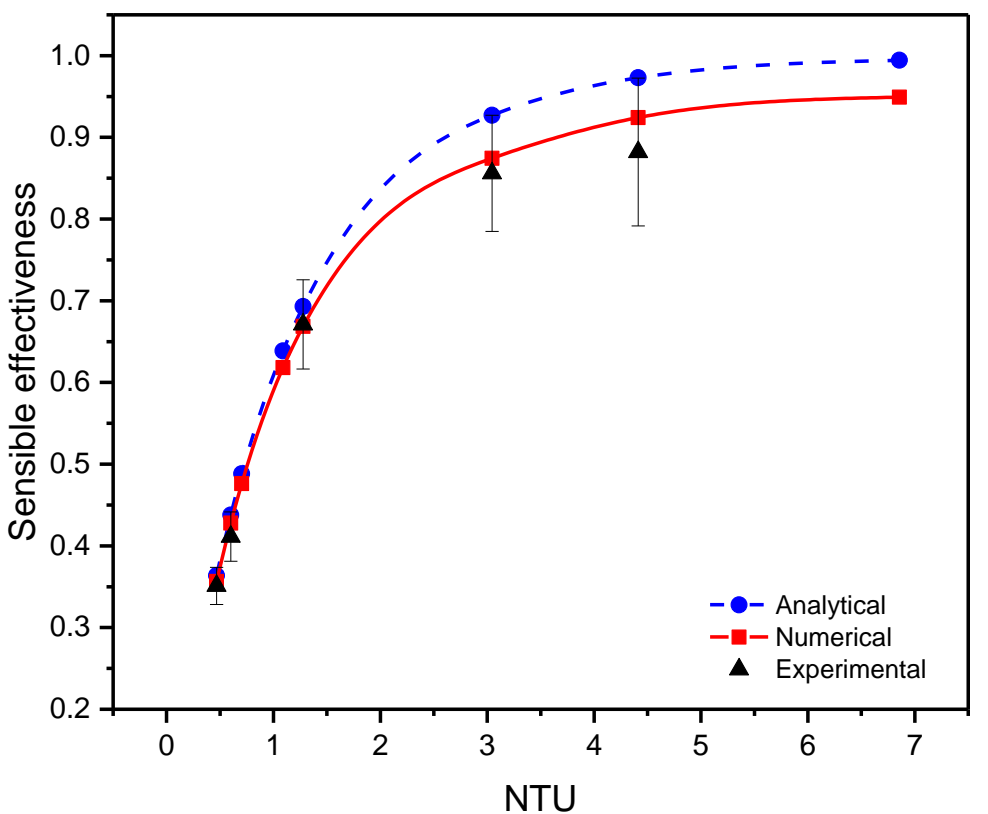




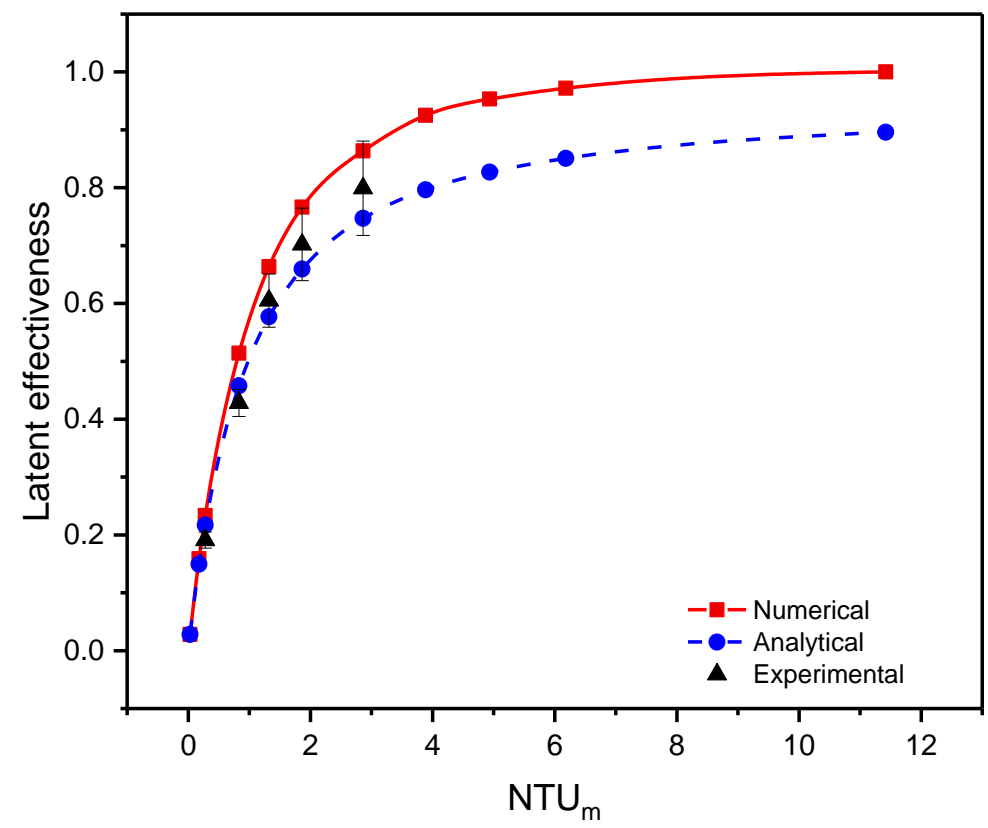

(B)

Fig. 5 Variations of sensible effectiveness (A) and latent effectiveness (B) under various $\mathrm{NTU}_{\mathrm{m}}$ based on experimental data, numerical results and analytical solutions.

\subsubsection{Comparison with previous studies}

This model is further compared with numerical results reported in the literature[57]. The validation considers a crossflow membrane dehumidifier operating under the inlet air temperature from $25.7^{\circ} \mathrm{C}$ to $35.2^{\circ} \mathrm{C}$, specific humidity of $0.015 \mathrm{~kg} / \mathrm{kg}$ to $0.022 \mathrm{~kg} / \mathrm{kg}$ and inlet air mass flow rate of 7.55 to $15.65 \mathrm{~kg} / \mathrm{h}$ using $\mathrm{LiCl}$ as the desiccant solution. Table 6 shows the comparisons between Zhang's model[57] and the model proposed in this paper under the above conditions. It can be found that the results of the outlet air temperature and the outlet solution temperature obtained from the model presented in this paper, are highly consistent with the results of Zhang's model[57], with maximum discrepancy of $2.9 \%$ for the outlet solution temperature, and $1.6 \%$ for the outlet air temperature.

To summarize, the proposed numerical model was shown to be consistent with experimental results, the analytical solution, and results from the literature. Hence, this model could be adopted to analyze the working performance of the PHFD studied in this research.

Table 6 Comparisons between Zhang's model [57] and the model proposed in this paper under the same conditions

\begin{tabular}{|c|c|c|c|c|c|c|c|c|c|}
\hline \multicolumn{4}{|c|}{ Operating conditions } & \multicolumn{6}{|c|}{ Parameters } \\
\hline \multirow[t]{2}{*}{$\dot{m}_{\text {sol }}$} & \multirow{2}{*}{$\dot{m}_{\text {air }}$} & \multirow[t]{2}{*}{$\mathrm{T}_{\text {air }, \mathrm{i}}$} & \multirow[t]{2}{*}{$\mathrm{T}_{\text {sol,i }}$} & \multicolumn{2}{|c|}{$\mathrm{T}_{\mathrm{air}, \mathrm{o}}$} & \multirow[t]{2}{*}{ Error(\%) } & \multicolumn{2}{|c|}{$\mathrm{T}_{\mathrm{sol}, \mathrm{o}}$} & \multirow[t]{2}{*}{ Error(\%) } \\
\hline & & & & $\begin{array}{c}\text { Zhang's } \\
\text { model }\end{array}$ & $\begin{array}{l}\text { This } \\
\text { model }\end{array}$ & & $\begin{array}{c}\text { Zhang's } \\
\text { model }\end{array}$ & $\begin{array}{l}\text { This } \\
\text { model }\end{array}$ & \\
\hline 9.69 & 6.36 & 33.9 & 24.9 & 25.99 & 25.65 & 1.3 & 32.44 & 32.90 & 1.4 \\
\hline 9.75 & 8.67 & 35.2 & 25.3 & 28.04 & 27.72 & 1.1 & 36.89 & 37.51 & 1.8 \\
\hline 9.66 & 12.22 & 34.9 & 25.2 & 29.58 & 29.54 & 0.1 & 37.78 & 38.52 & 1.9 \\
\hline
\end{tabular}




\begin{tabular}{cccccccccc}
8.79 & 15.65 & 33.7 & 25.2 & 30.37 & 30.83 & 1.6 & 36.72 & 37.86 & 2.9 \\
5.29 & 12.45 & 33.8 & 25.5 & 33.3 & 33.79 & 1.2 & 40.42 & 40.23 & 0.5 \\
10.19 & 7.55 & 35.3 & 24.5 & 26.5 & 26.09 & 1.5 & 35.27 & 35.94 & 1.9 \\
9.53 & 7.45 & 32.8 & 24.6 & 26.37 & 25.95 & 1.2 & 33.68 & 34.08 & 1.0 \\
9.67 & 7.43 & 29.8 & 24.6 & 26.39 & 25.73 & 2.2 & 32.39 & 32.59 & 0.6 \\
9.67 & 7.45 & 27.2 & 25.6 & 26.51 & 26.44 & 0.3 & 30 & 31.17 & 3.6 \\
9.45 & 7.66 & 25.7 & 25.4 & 26.31 & 26.22 & 0.3 & 29.46 & 30.26 & 2.7 \\
\hline
\end{tabular}

450

451

452

453

454

455

456

457

458

459

460

461

462

463

464

465

466

467

468

\subsection{Effect of the inlet air conditions}

According to the numerical analysis results, the inlet air conditions (i.e. inlet air velocity $V_{\text {air }, i}$, and temperature $\left.T_{\text {air }, i}\right)$ are crucial parameters of the proposed PHFD. Fig 6-8 show the variations of 4 parameters: sensible effectiveness, latent effectiveness, outlet air temperature and specific humidity difference under various air velocities. As shown in Fig. 6, with increasing air velocity, the latent heat capacity ratio $\left(\mathrm{m}_{\mathrm{lat}}\right)$ and sensible heat capacity ratio $\left(\mathrm{m}_{\text {sen }}\right)$ will increase while the $\mathrm{NTU}_{\mathrm{m}}$ and NTU will decrease. As demonstrated in Fig. 7, a higher inlet air velocity will cause a rise of the outlet air temperature and the specific humidity difference between the inlet and the outlet air. This results in the increase of the sensible and latent effectiveness, as shown in Fig. 8 . For example, at the inlet air relative humidity of $60 \%$ and dry bulb temperature of $35^{\circ} \mathrm{C}$, when the inlet air velocity increases from $1.5 \mathrm{~m} / \mathrm{s}$ to $4.5 \mathrm{~m} / \mathrm{s}$, the specific humidity difference between the inlet air and the outlet air are $0.0040 \mathrm{~kg} / \mathrm{kg}, 0.0030 \mathrm{~kg} / \mathrm{kg}, 0.0022 \mathrm{~kg} / \mathrm{kg}, 0.0018 \mathrm{~kg} / \mathrm{kg}$ respectively. The sensible and latent effectiveness decreases from 0.381 to 0.03 and 0.383 to 0.178 , respectively. This is because the higher air velocity leads to the reduction of the contact duration between the incoming air and the desiccant solution inside the PHFD. This results in less effective heat and mass transfer, which is reflected in the reduced sensible and latent effectiveness, as shown in Fig.8.

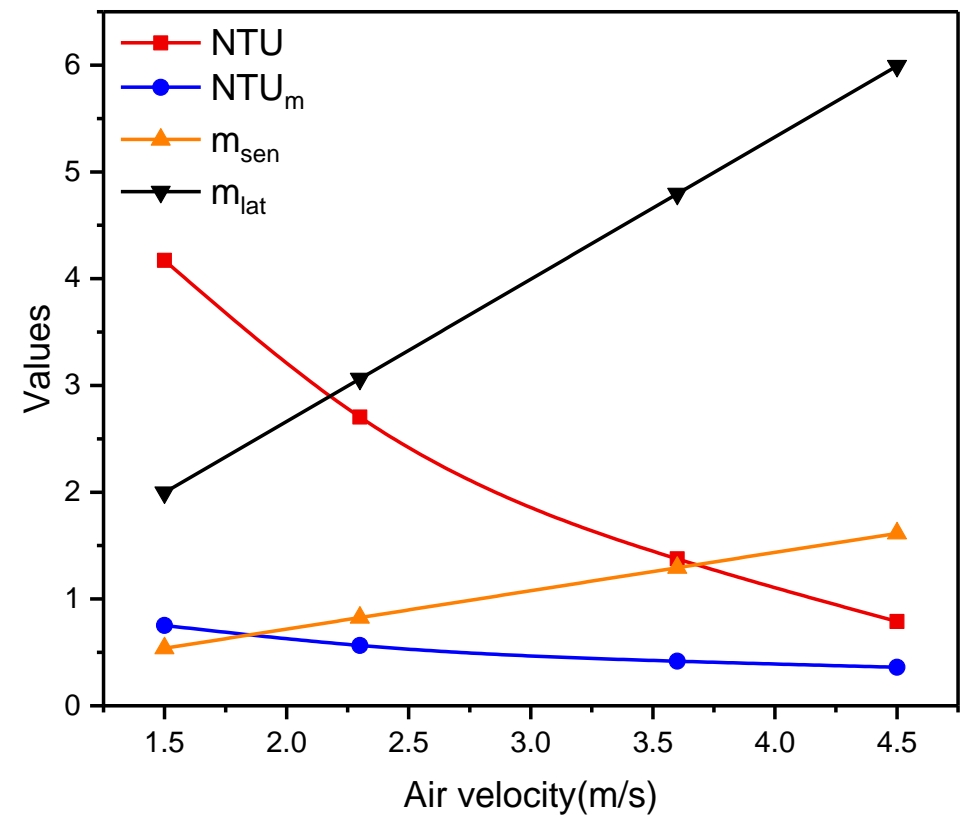

Fig. 6 The dimensionless parameters variations under different air velocities $\left(\mathrm{T}_{\mathrm{air}, \mathrm{i}}=35^{\circ} \mathrm{C}\right.$, 


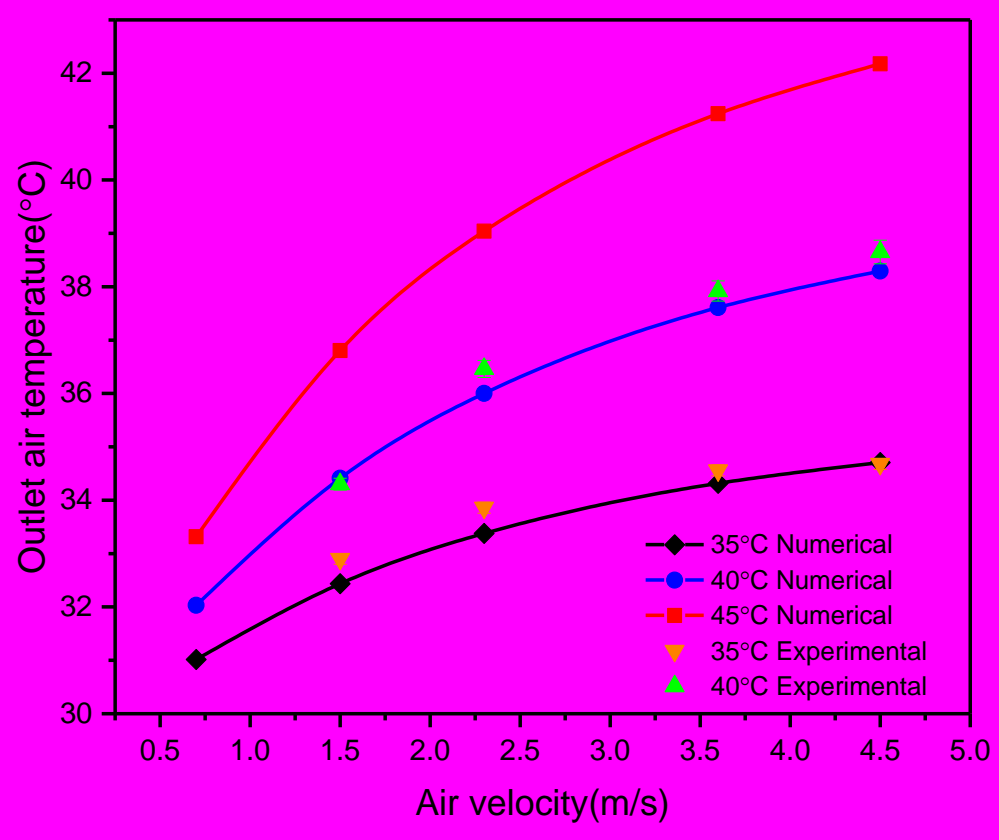

(A) (error bars in 35 degree $C$ experimental results should be shown in this figure, the same as 40 degree C's error bar)

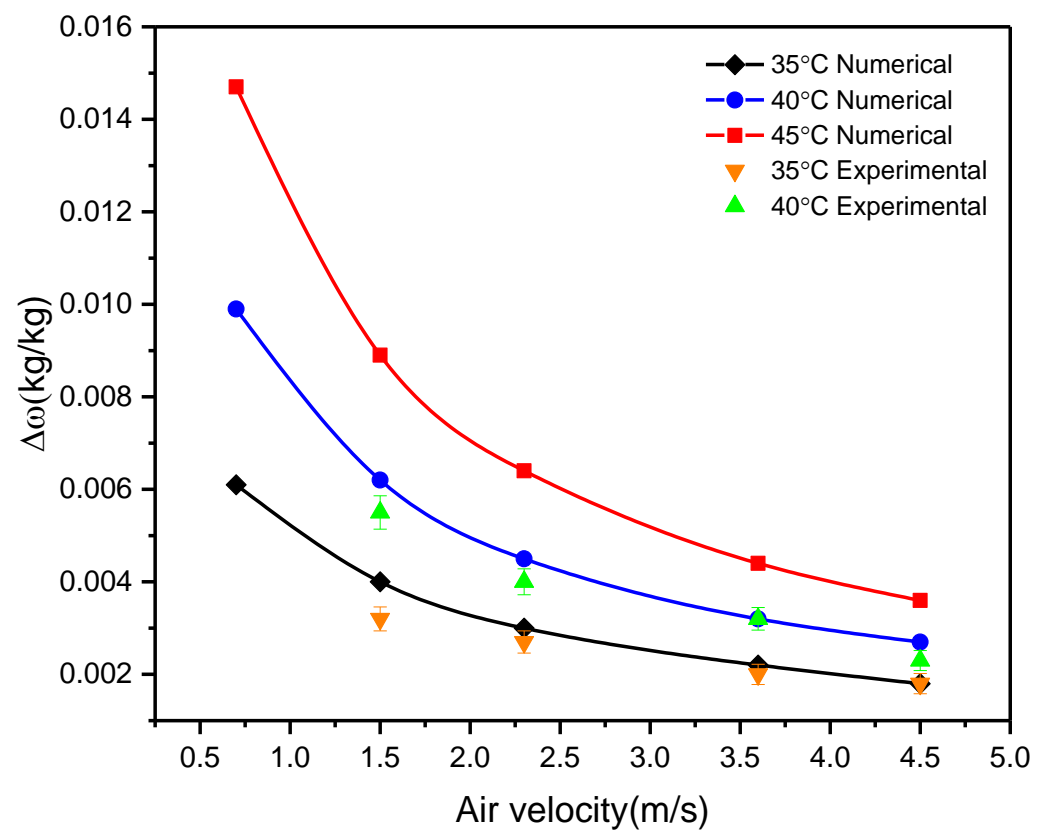

478 Fig. 7 The numerically obtained outlet air temperature (A), and specific humidity difference 

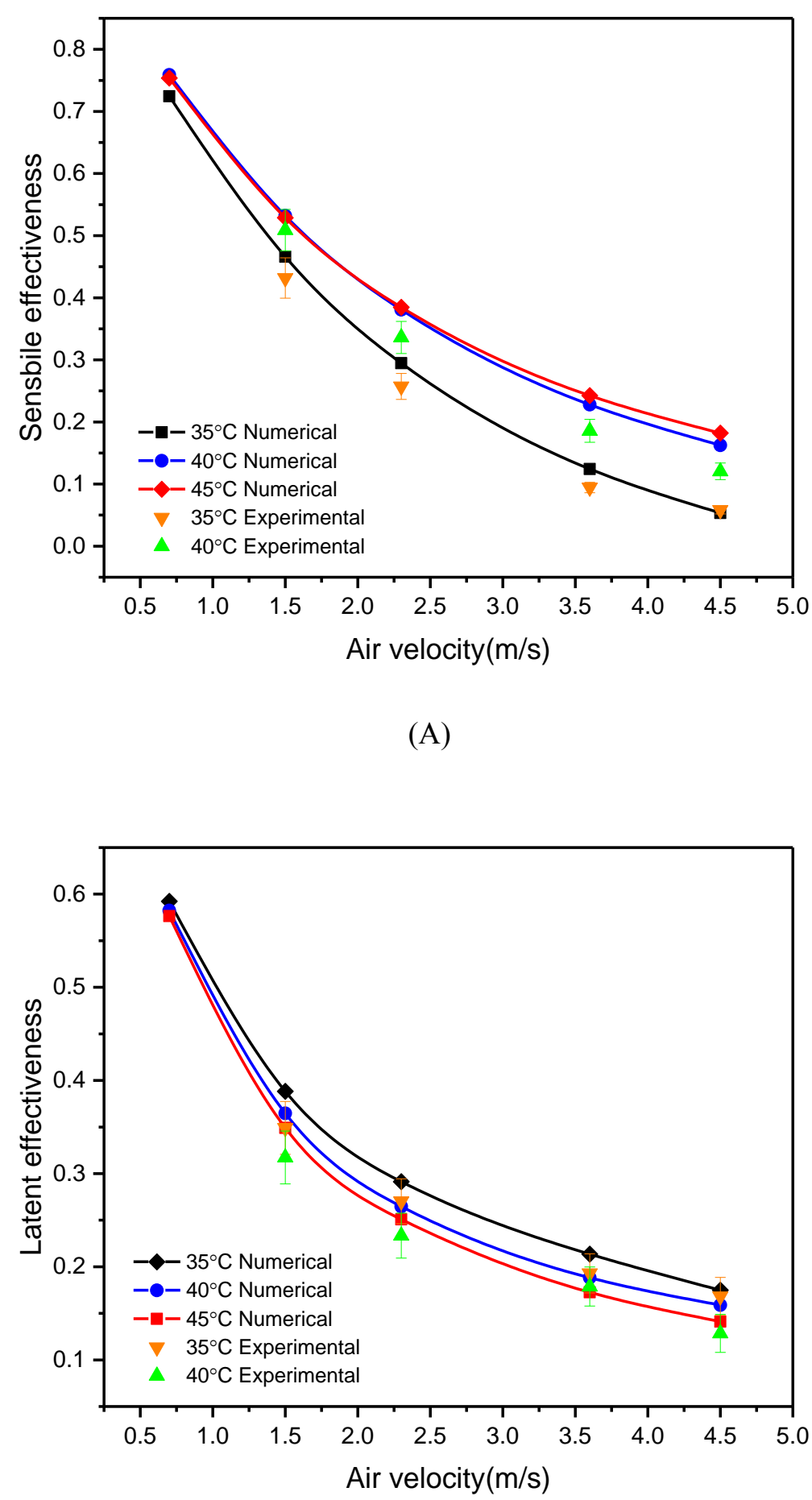

Fig. 8 The numerically obtained sensible effectiveness (A), and latent effectiveness (B), under 
temperature. For instance, when the air velocity is fixed at $3.6 \mathrm{~m} / \mathrm{s}$, for the inlet air temperature of $35^{\circ} \mathrm{C}, 40^{\circ} \mathrm{C}$ and $45^{\circ} \mathrm{C}$, the sensible effectiveness is $0.12,0.23$ and 0.24 , respectively. In contrast, as depicted in Fig. 8 (B), when the solution concentration and the inlet air velocity are fixed, a higher inlet air temperature results in lower latent effectiveness. For instance, the latent effectiveness only decreases by $1.6 \%$ and $1 \%$ respectively when the inlet air temperature increases from $35^{\circ} \mathrm{C}$ to $40^{\circ} \mathrm{C}$ and 40 to $45^{\circ} \mathrm{C}$ at $0.7 \mathrm{~m} / \mathrm{s}$ air velocity, which is negligible. On the contrary, $\Delta \omega$ increases with the improvement of inlet air temperature when the inlet air velocity is fixed at $0.7 \mathrm{~m} / \mathrm{s}$. The reason is that the increase of the inlet air temperature will lead to higher specific humidity, while the inlet equilibrium humidity of the solution remains unchanged and increases the vapor pressure difference indirectly.

\subsection{Effect of the liquid desiccant solution inlet conditions}

The temperature of the solution and its concentration also play crucial roles in the dehumidification performance. Fig.9 shows the variations of the sensible and latent effectiveness under several inlet solution temperatures at various concentrations. As it can be found from Fig.9 (A), the sensible effectiveness drops with the increase of the solution temperature. For example, at a $57 \%$ concentration, the sensible effectiveness varies from 0.4 to 0.3 when the solution temperature changes from $20.5^{\circ} \mathrm{C}$ to $28.5^{\circ} \mathrm{C}$. It should be noted that at higher solution temperatures, high concentration solutions are more sensitive to temperature changes. For instance, as the temperature of the solution rises from $26.5^{\circ} \mathrm{C}$ to $28.5^{\circ} \mathrm{C}$, the sensible effectiveness at a $57 \%$ concentration drops by $15 \%$. In contrast, when the concentration is $62 \%$, the corresponding decrease is $32 \%$. In Fig.9(B), it can be seen that the latent effectiveness almost remains constant as the solution temperature rises. For instance, at a $62 \%$ concentration, the latent effectiveness is $0.203,0.200,0.200,0.200,0.198$ at the solution temperature of $20.5^{\circ} \mathrm{C}, 22.5^{\circ} \mathrm{C}, 24.5^{\circ} \mathrm{C}, 26.5^{\circ} \mathrm{C}, 28.5^{\circ} \mathrm{C}$, respectively. This is because, according to Eq. (35), the solution equilibrium humidity $(\mathrm{KCOOH})$ is related to its temperature and concentration. Although the vapor pressure will naturally increase with the solution temperature, the solution equilibrium humidity will also increase, and will thus reduce both the nominator and denominator of Eq. (35). In addition, lower solution concentration leads to lower latent effectiveness, for example, at $26.5^{\circ} \mathrm{C}$, the latent effectiveness is $0.22,0.20$, and 0.18 for the concentration ratios of $67 \%, 62 \%, 57 \%$, respectively. 


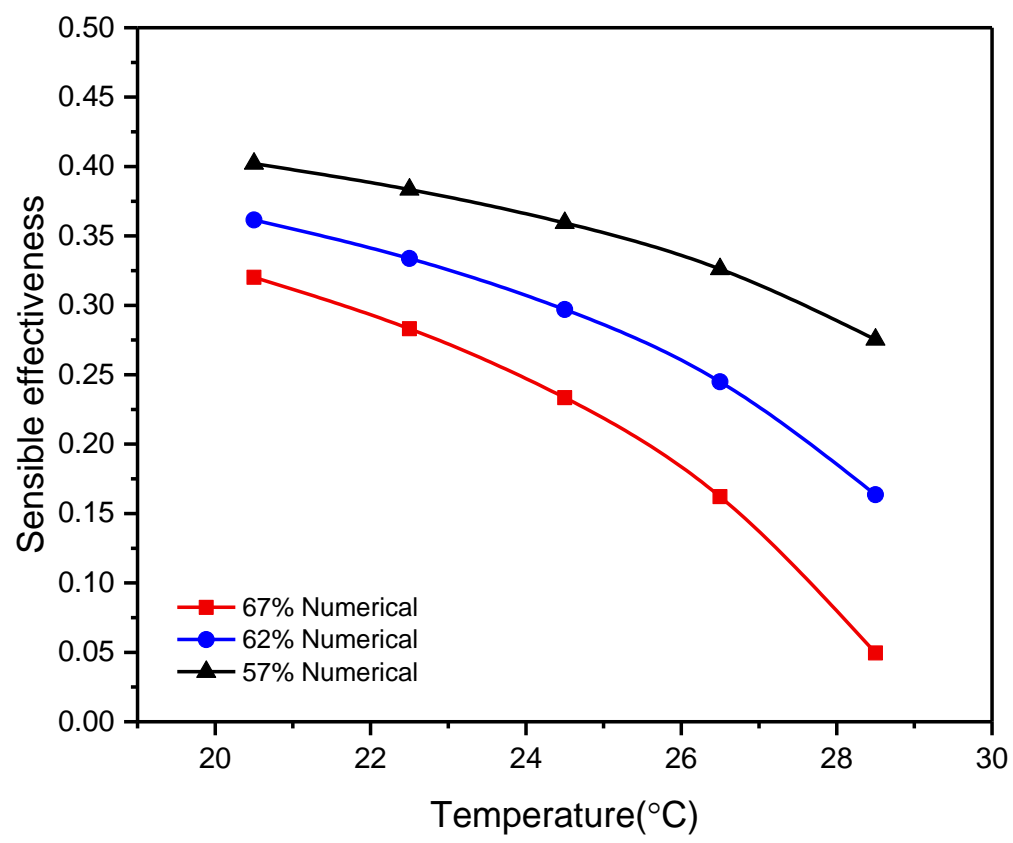

519

520

521

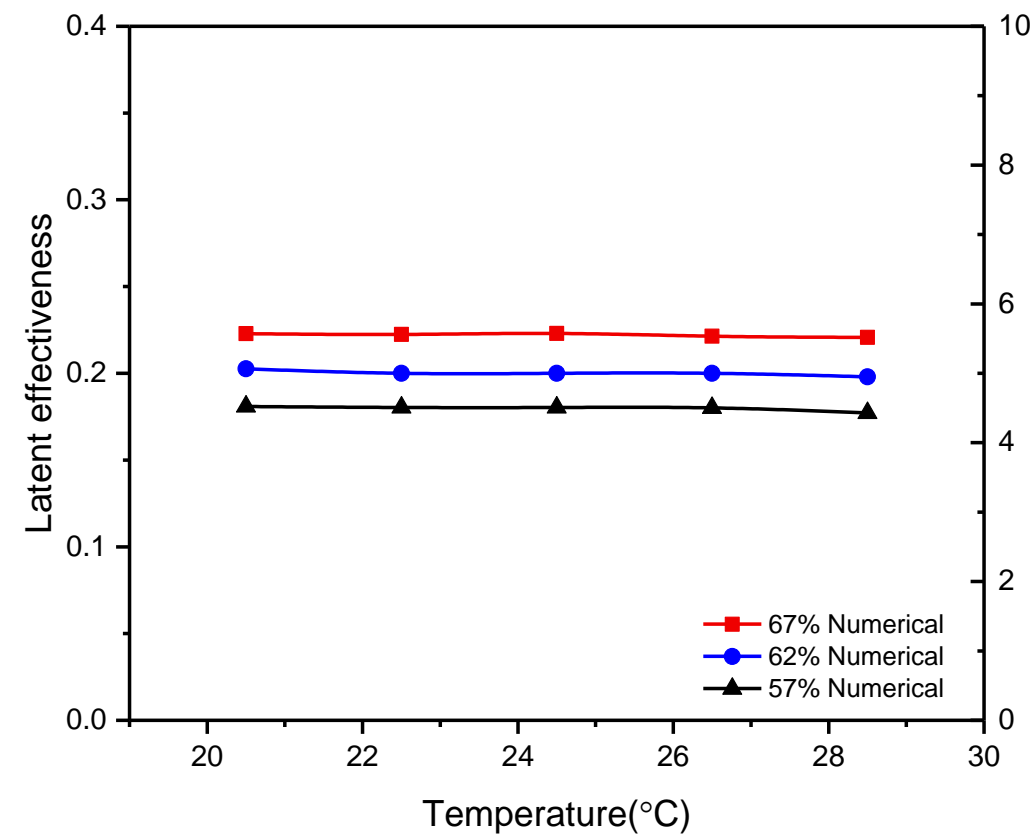

(A)

\section{(B)}

Fig. 9 Variations of sensible effectiveness (A), and latent effectiveness (B), for several inlet solution temperatures at various solution concentrations $\left(\mathrm{T}_{\mathrm{air}, \mathrm{i}}=35^{\circ} \mathrm{C}, \mathrm{RH}_{\mathrm{air}, \mathrm{i}}=60 \%\right.$, $\mathrm{V}_{\text {air }, i}=3.6 \mathrm{~m} / \mathrm{s}, \dot{m}_{s o l, i}=0.028 \mathrm{~kg} / \mathrm{s}$ ) 


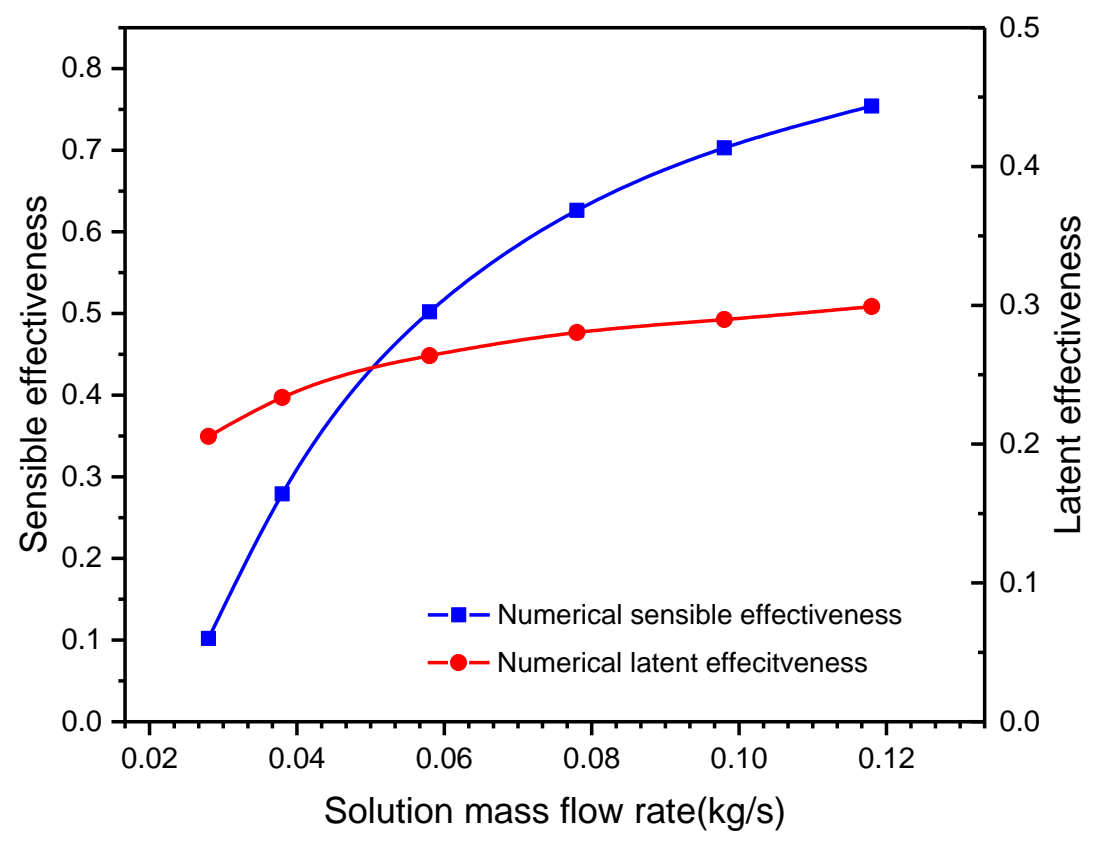

527

Fig 10 Variations of latent and sensible effectiveness with the solution mass flow rate $\left(\mathrm{T}_{\text {air },}=\right.$

$$
35^{\circ} \mathrm{C}, \mathrm{T}_{\mathrm{sol}, \mathrm{i}}=29.5^{\circ} \mathrm{C}, \mathrm{RH}_{\mathrm{air}, \mathrm{i}}=60 \%, \mathrm{X}_{\mathrm{sol}}=62 \%, \mathrm{~V}_{\text {air }, \mathrm{i}}=3.6 \mathrm{~m} / \mathrm{s} \text { ) }
$$

Fig.10 shows the relationship between solution mass flow rate and effectiveness, including sensible effectiveness and latent effectiveness. With the increase of the solution mass flow rate, the sensible effectiveness will increase dramatically. For instance, when the air mass flow rate increases from $0.02 \mathrm{~kg} / \mathrm{s}$ to $0.012 \mathrm{~kg} / \mathrm{s}$, the sensible effectiveness shows a 7.7 times increase. This is because a higher solution flow leads to a lower average solution temperature, and the outlet air temperature will decrease. As for the latent effectiveness, this will also increase with the solution mass flow rate. For example, the sensible effectiveness only increases by $46 \%$ when the solution flow rate rises from $0.02 \mathrm{~kg} / \mathrm{s}$ to $0.012 \mathrm{~kg} / \mathrm{s}$. This is because the increase of the solution mass flow will result in the lower average equilibrium vapour pressure of the desiccant solution, and a higher mass transfer capacity will be obtained. It should be noted that when the solution mass flow rate is over $0.08 \mathrm{~kg} / \mathrm{s}$, the growth rate of both the sensible and latent effectiveness will drop. As far as the sensible effectiveness is concerned, the reason for this is that the average solution temperature has a limit value, which is infinitely close to the initial solution temperature when the solution mass flow rate is much bigger than the air flow rate, hence the heat transfer driving force becomes weaker. For the latent effectiveness, the larger the solution mass flow rate, the more moisture will be absorbed by the desiccant, and the value of the air-specific humidity will be close to the equilibrium specific humidity of the desiccant solution, hence the ability of absorbing the moisture will become weaker.

\subsection{Effects of the dimensionless parameters}

The influences of the air to solution specific humidity ratio $\omega_{r}^{*}$ on the outlet air temperature, the sensible effectiveness, the specific humidity difference, the moisture removal rate, the latent effectiveness, and the total effectiveness are demonstrated in Figs. 11-13. The other initial air and solution conditions were invariable, the air velocity at the inlet was fixed at $0.7 \mathrm{~m} / \mathrm{s}$, the 
inlet air temperature was fixed at $35^{\circ} \mathrm{C}$, and the inlet solution mass flow rate was $0.028 \mathrm{~kg} / \mathrm{s}$. As shown in Fig. 11, the air temperature at the outlet rises from $30.6^{\circ} \mathrm{C}$ to $31.8^{\circ} \mathrm{C}$ (an increase of $3.9 \%$ ) and the sensible effectiveness drops from 0.79 to 0.57 (a fall of $22 \%$ ) when the $\omega_{r}^{*}$ varies between 1.46 and 2.12. Inspection of Fig. 12 reveals that both the air specific humidity difference and the moisture removal rate both increase when the $\omega_{r}^{*}$ increases. For instance, the air specific humidity difference is $0.0053 \mathrm{~kg} / \mathrm{kg}, 0.0065 \mathrm{~kg} / \mathrm{kg}, 0.0079 \mathrm{~kg} / \mathrm{kg}, 0.0089 \mathrm{~kg} / \mathrm{kg}$, $0.0098 \mathrm{~kg} / \mathrm{kg}$ and $0.0106 \mathrm{~kg} / \mathrm{kg}$ at $\omega_{r}^{*}$ of $1.46,1.62,1.78,1.88,1.99$ and 2.12 , respectively, and the rate of moisture removal rised by $104 \%$ (from $0.21 \mathrm{~kg} / \mathrm{s}$ to $0.43 \mathrm{~kg} / \mathrm{s}$ ) at each $\omega_{r}^{*}$. The reason is that a higher $\omega_{r}^{*}$ reflects a higher water vapor pressure. No matter whether the inlet air specific humidity increases or the inlet solution concentration decreases, a greater vapor pressure difference between incoming air and desiccant solution is built. This leads to the solution attracting more moisture from the inlet air, which increases the specific humidity difference between the inlet air and the outlet air. When the desiccant solution absorbs more vapor, a higher amount of latent heat will be released. This results in a smaller temperature difference between the incoming air and the desiccant solution, which makes the temperature drop gradually.

As shown in Fig. 13, the impact of the air to solution specific humidity ratio on the latent effectiveness is negligible. For example, the latent effectiveness remains around 0.61 , when $\omega_{r}^{*}$ changes from 1.45 to 2.15 . On the other hand, the total effectiveness decreases with the increase of $\omega_{r}^{*}$. This is because although the air-specific humidity or solution equilibrium humidity increase dramatically with the rise of $\omega_{r}^{*}$, the air specific humidity difference between the air and the solution at the inlet also grows. Thus, the latent and total effectiveness are not affected by $\omega_{r}^{*}$.

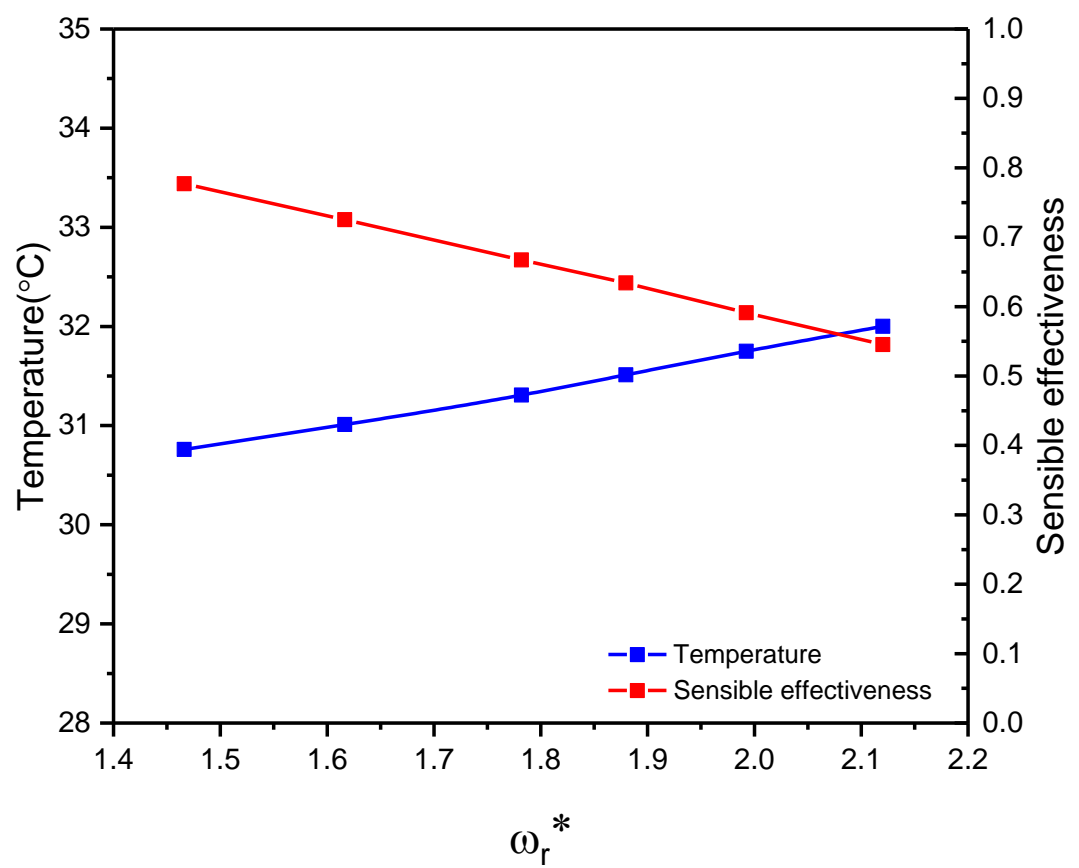

Fig 11 Variation of the outlet air temperature and sensible effectiveness with the air to solution specific humidity ratio $\left(\mathrm{T}_{\text {air }, i}=35^{\circ} \mathrm{C}, \mathrm{T}_{\text {sol }, i}=29.5^{\circ} \mathrm{C}, \dot{m}_{\text {sol, } i}==0.028 \mathrm{~kg} / \mathrm{s}, \mathrm{V}_{\text {air }, i}=3.6 \mathrm{~m} / \mathrm{s}\right)$ 


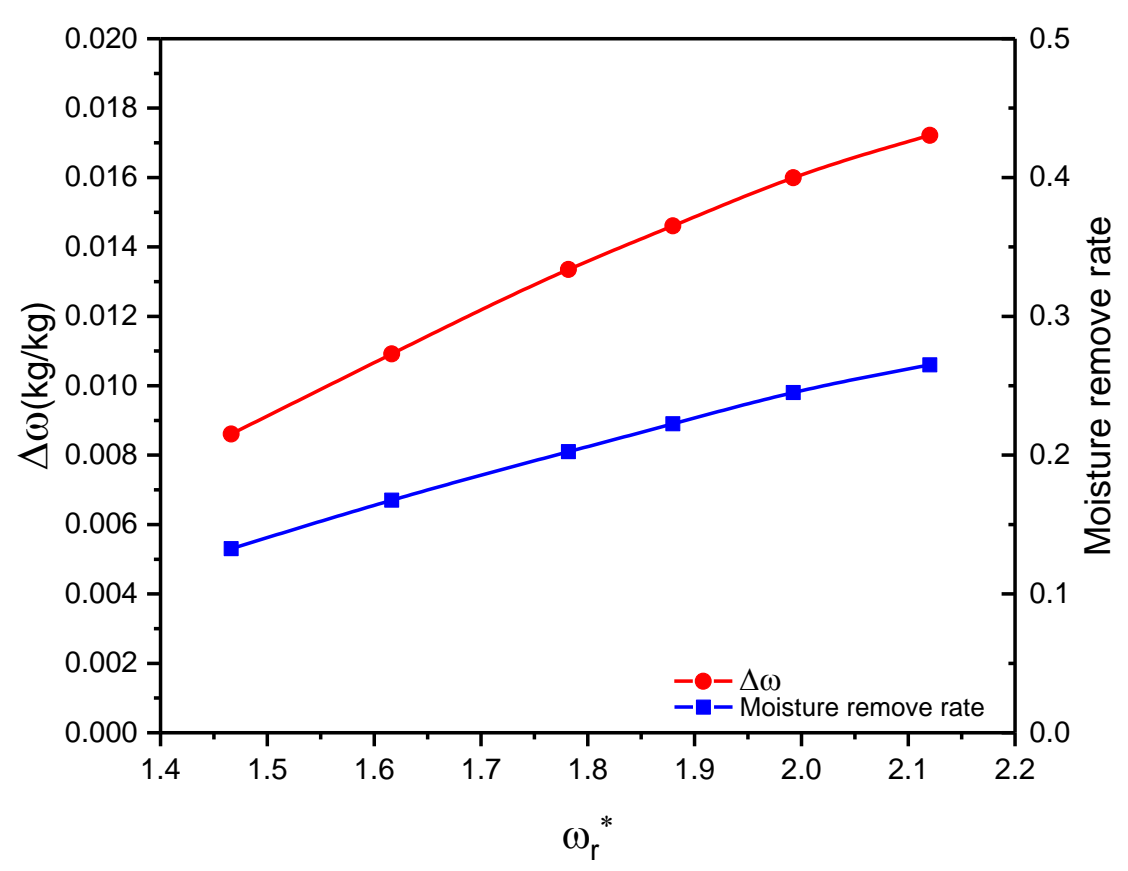

Fig 12 Variation of the specific humidity difference and moisture removal rate with the air to solution specific humidity ratio $\left(\mathrm{T}_{\text {arr },}=35^{\circ} \mathrm{C}, \mathrm{T}_{\text {sol, }, \mathrm{i}}=29.5^{\circ} \mathrm{C}, \dot{m}_{\text {sol, } i}=0.028 \mathrm{~kg} / \mathrm{s}, \mathrm{V}_{\text {air }, i}=3.6 \mathrm{~m} / \mathrm{s}\right)$

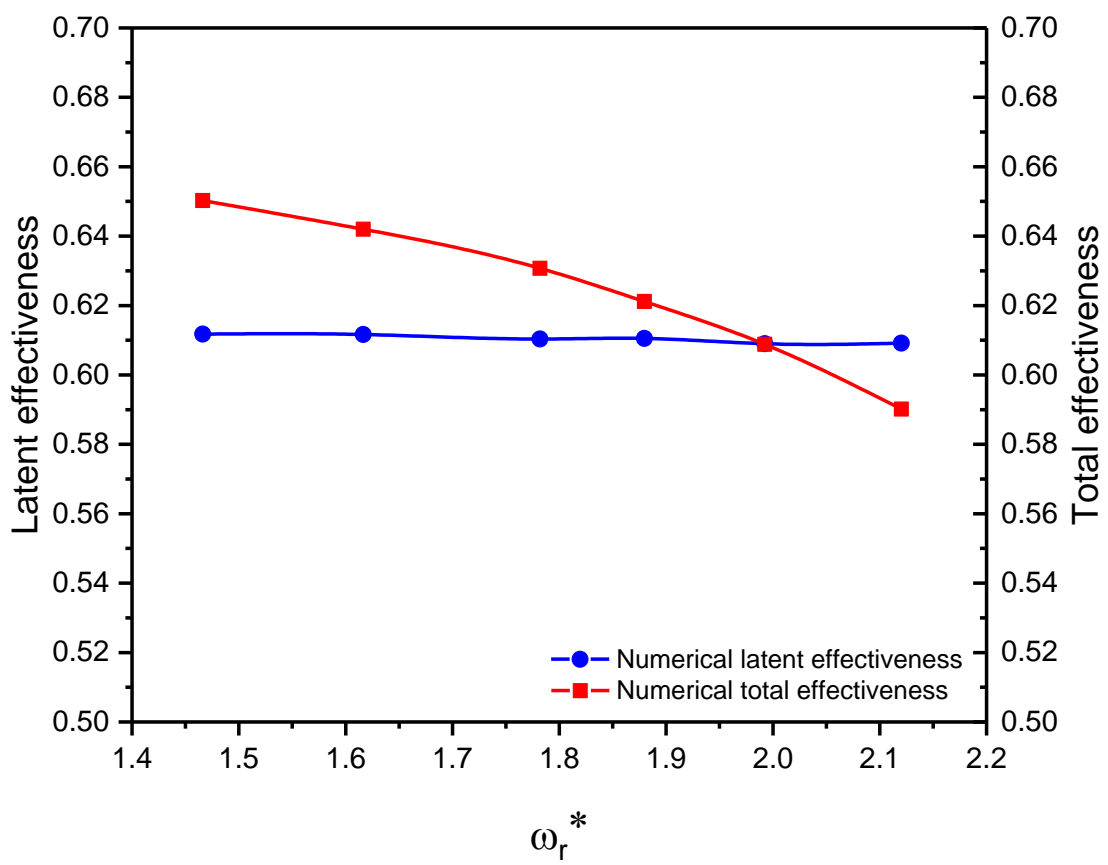

Fig 13 Variation of the latent effectiveness and total effectiveness with the air to solution specific humidity ratio $\left(\mathrm{T}_{\text {air }, i}=35^{\circ} \mathrm{C}, \mathrm{T}_{\text {sol, },}=29.5^{\circ} \mathrm{C}, \dot{m}_{s o l, i}=0.028 \mathrm{~kg} / \mathrm{s}, \mathrm{V}_{\text {air }, i}=3.6 \mathrm{~m} / \mathrm{s}\right)$

To summarize, the variation of air velocity has a strong impact on $T_{a o}, \omega_{a o}, N T U, N T U_{m}, m_{\text {sen }}$, $\mathrm{m}_{\text {lat }}$, and has a significant effect on the latent effectiveness and the sensible effectiveness. The sensible effectiveness and total effectiveness are less related to $\omega_{r}^{*}$. The moisture removal rate and the sensible effectiveness also change significantly with the variations of $\omega_{r}^{*}$. In addition, 
the change of air specific humidity difference and the inlet and outlet air temperature difference are closely related to $\omega_{r}^{*}$. This implies that changes of the $\omega_{r}^{*}$ within a certain range (i.e. 1.45 to 2.15 ) is preferable for increasing the dehumidification performance without reducing the latent effectiveness.

\subsection{Temperature and humidity contour}

Temperature and humidity ratio contours of both the air and the solution are plotted in Figs.1415 , based on the modeling results. The inlet air temperature, specific humidity ratio and mass flow rate are $35^{\circ} \mathrm{C}, 0.0215 \mathrm{~kg} / \mathrm{kg}$ and $0.0407 \mathrm{~kg} / \mathrm{s}$, respectively, and the inlet solution temperature is $29.5^{\circ} \mathrm{C}$, while the inlet equilibrium humidity ratio of the solution is $0.01076 \mathrm{~kg} / \mathrm{kg}$, and the solution mass flow rate is $0.028 \mathrm{~kg} / \mathrm{s}$. In Figs. 14-15, the bottom boundary line indicates the solution inlet and the right boundary line indicates the air inlet. Fig. 14 indicates that the air specific humidity decreases from the inlet to the outlet. It is interesting to observe that the drop rate of the air specific humidity slows down from the solution inlet to the solution outlet. This is mainly because at the solution inlet, the solution has the lowest equilibrium humidity ratio, which means that the solution can maximally absorb moisture from the incoming air. In contrast, at the outlet, the desiccant solution has a much higher equilibrium humidity ratio. As for the air flow, the temperature decreases along the $\mathrm{x}$ axis, and reaches the lowest temperature (top right corner of the model) at nearly $29.5^{\circ} \mathrm{C}$. It should also be noted that at the corner between solution outlet and air inlet, the air temperature is slightly higher than the inlet temperature. This is due to the accumulation of latent heat released by moisture, and sensible heat from the air, which leads to the rise of the solution temperature as indicated in Fig. 14. As seen, the solution temperature and equilibrium humidity ratio both increase from solution inlet to solution outlet and reach the highest value $\left(36.3^{\circ} \mathrm{C}\right.$ and $0.01606 \mathrm{~kg} / \mathrm{kg}$, respectively) at the corner between solution outlet and air inlet of the model. The rate of change (from solution inlet to solution outlet) slows down from the air inlet to the air outlet. 

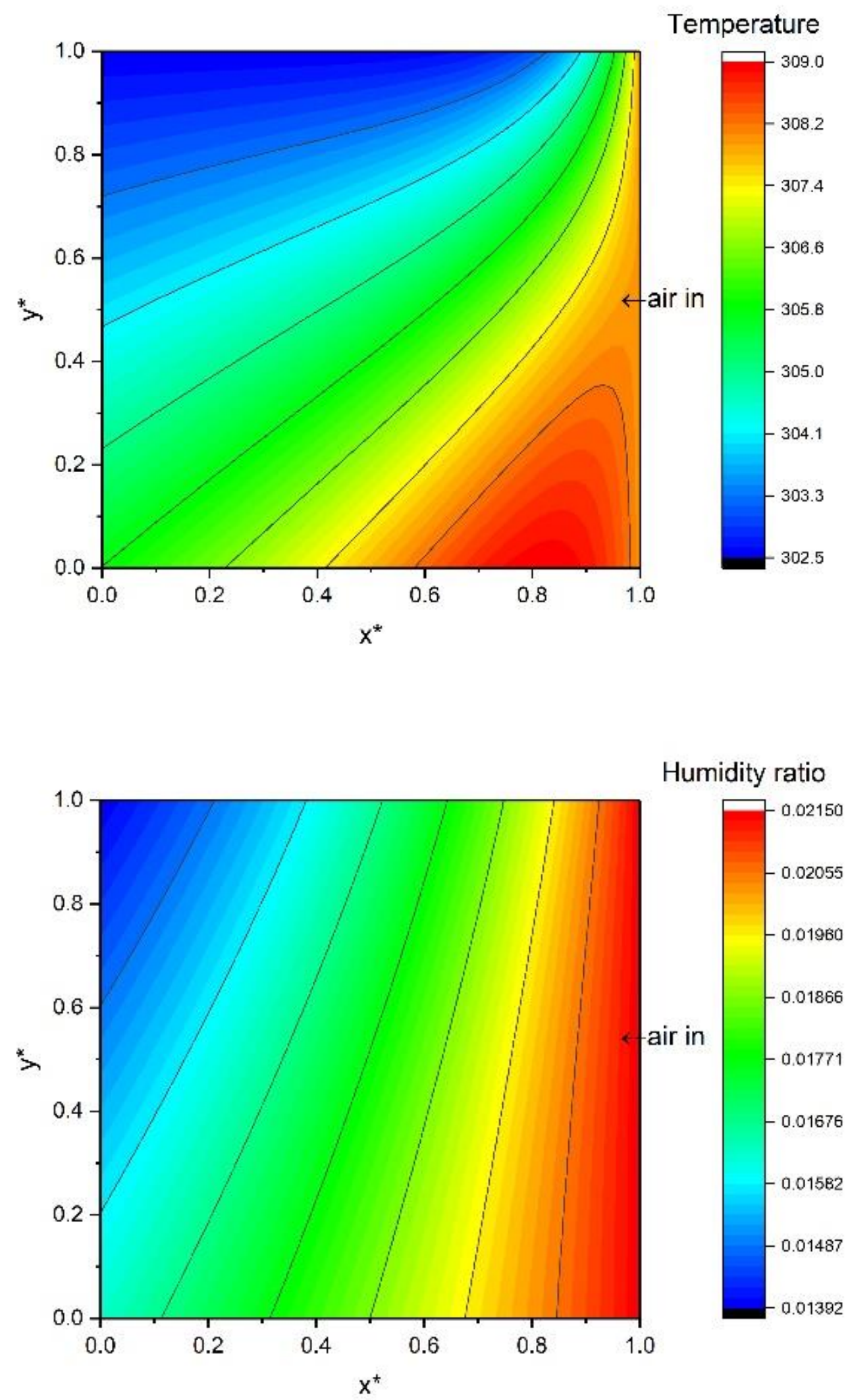

Fig. 14 Air temperature and humidity ratio contour 

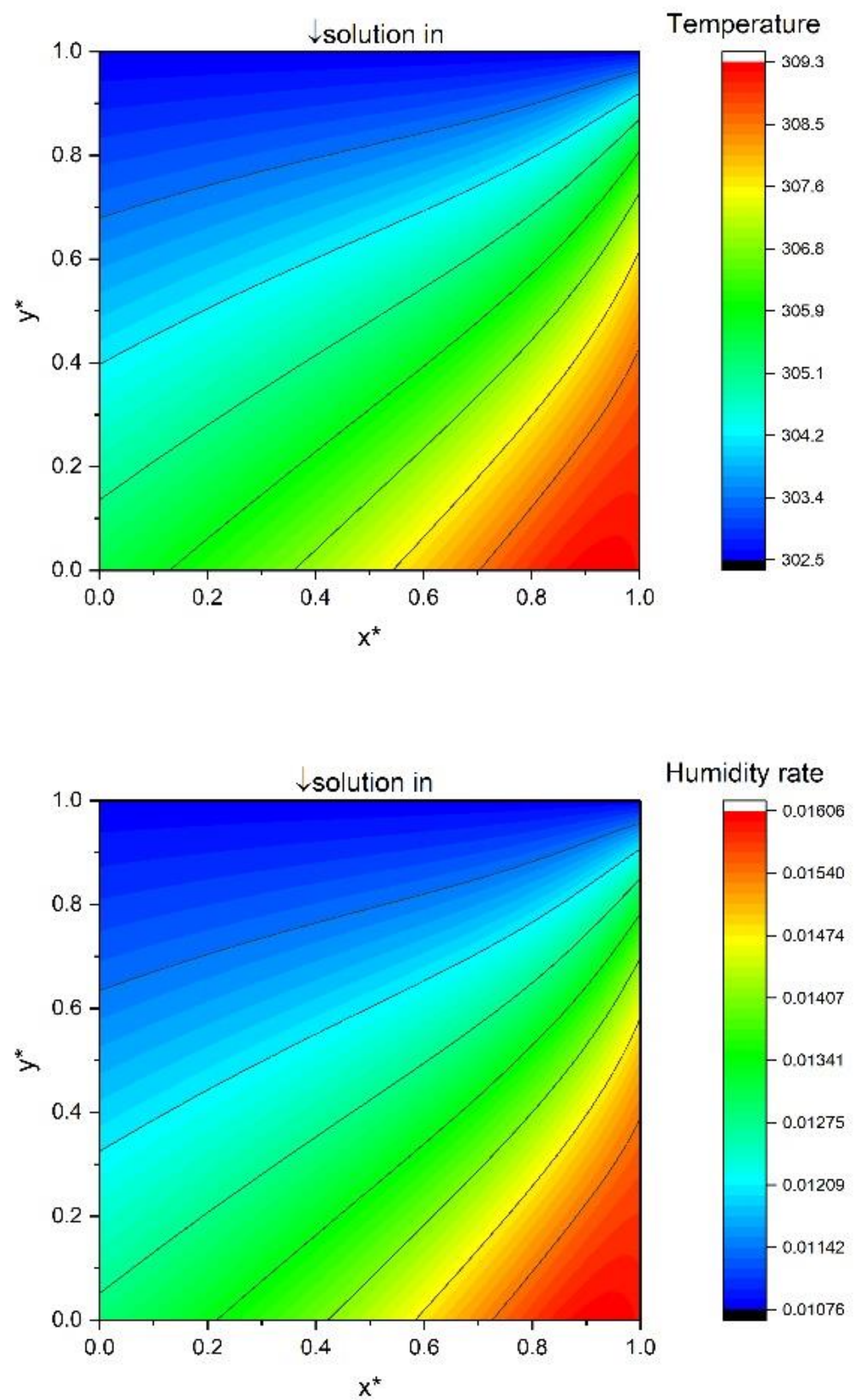

Fig. 15 Solution temperature and equilibrium humidity ratio contour 
Fig. 16 depicts the simulated outlet air temperature and specific humidity as a function of the number of fibers in the proposed liquid desiccant PHFD, with the inlet air $\mathrm{RH}=60 \%$ and inlet air temperature fixed at $30^{\circ} \mathrm{C}, 35^{\circ} \mathrm{C}$ and $40^{\circ} \mathrm{C}$, respectively. Calculations have been performed based on the square cross section of the dehumidifier with fiber numbers increasing from 400 to 8100 . Fig. 16 shows two different solutions to air mass flow ratios which represent the two lowest air velocities $\left(\dot{m}_{\text {sol }} / \dot{m}_{\text {air }}=10\right.$ and $\left.\dot{m}_{\text {sol }} / \dot{m}_{\text {air }}=5\right)$ applied in this research. Table 7 summarizes the outlet air conditions together with the sensible and latent effectiveness at the inlet air temperature of $35^{\circ} \mathrm{C}$, specific humidity of $0.0215 \mathrm{~kg} / \mathrm{kg}$ and solution inlet temperature

632

633

634

635

636

637

638

639

640

641

642

643

644

645

646

647

648

649

650

651

652

653

654 of $25^{\circ} \mathrm{C}$. It can be seen that as the fiber number goes beyond 3000 , the outlet air temperature, as well as the sensible and latent effectiveness maintain roughly the same value. This indicates that the optimum fiber number could be identified at around 3000 for lower air mass flow rate, which is associated with more effective heat and mass transfer. As the inlet air mass flow rate increases, the incoming air will have less time to be exposed to the desiccant solution, therefore more fibers with larger surface areas are required to obtain higher sensible and latent effectiveness.

Fig. 16 and Table 7 can be useful in the practical design stage of polymer hollow fiber integrated liquid desiccant dehumidification systems. It can help designers to obtain the desired number of fibers by referring to the required outlet air temperature shown in Fig. 16 or based on the required sensible and latent effectiveness indicated in Table 7, without having to repeat the iterative simulations. For instance, as shown in Fig. 16 (C), with inlet air temperature at $40^{\circ} \mathrm{C}$, approximately 1750 and 2380 fibers would be required to achieve the outlet air temperature of $30^{\circ} \mathrm{C}$, respectively, for $\dot{m}_{\text {sol }} / \dot{m}_{\text {air }}=10$ and $\dot{m}_{\text {sol }} / \dot{m}_{\text {air }}=5$. At $\dot{m}_{\text {sol }} / \dot{m}_{\text {air }}=10$, the dehumidifier with 1750 fibers will provide a total fiber surface area of $5.28 \mathrm{~m}^{2}$. This can be achieved by inserting those fibers into a cylindrical module with the module cross section diameter equal to $0.28 \mathrm{~m}$. As the incoming air mass flow rate doubles $\left(\dot{m}_{\text {sol }} / \dot{m}_{\text {air }}=5\right)$, in order to achieve the same outlet temperature of $30^{\circ} \mathrm{C}$, the required cylindrical module cross section diameter should be increased to $0.36 \mathrm{~m}$. This means that larger fiber surface area will be required at higher inlet air mass flow rate. Similarly, by making use of Table 7, based on the required sensible and latent effectiveness for different operational conditions, the designer could easily select the relevant $\dot{m}_{\text {sol }} / \dot{m}_{\text {air }}$ and fibers number. 


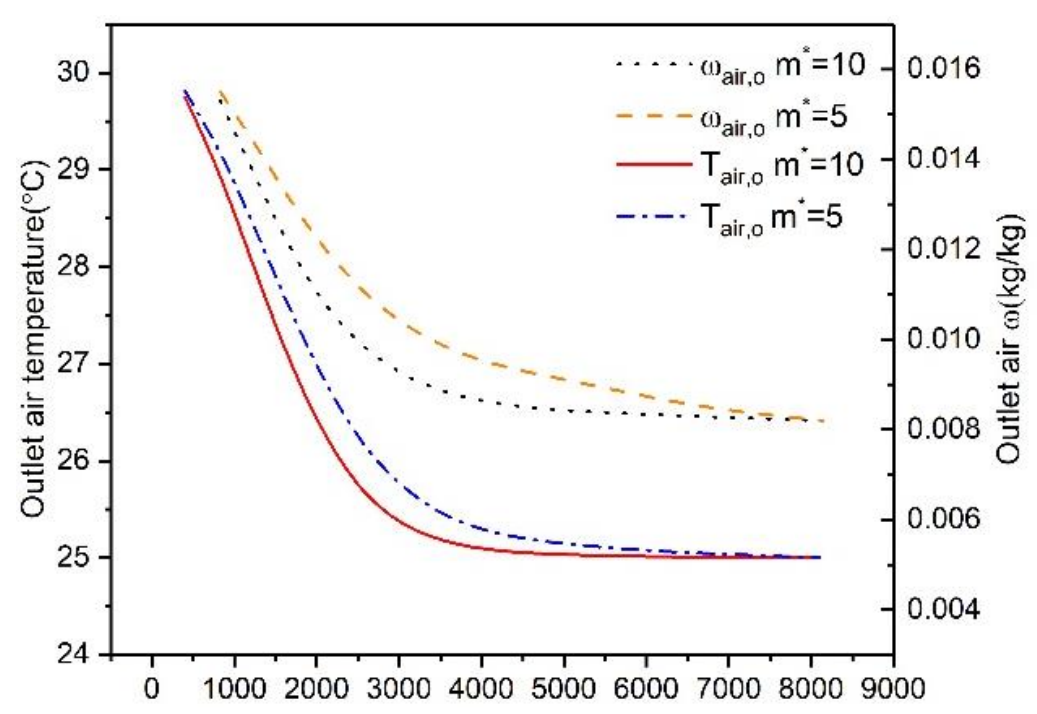

(A)

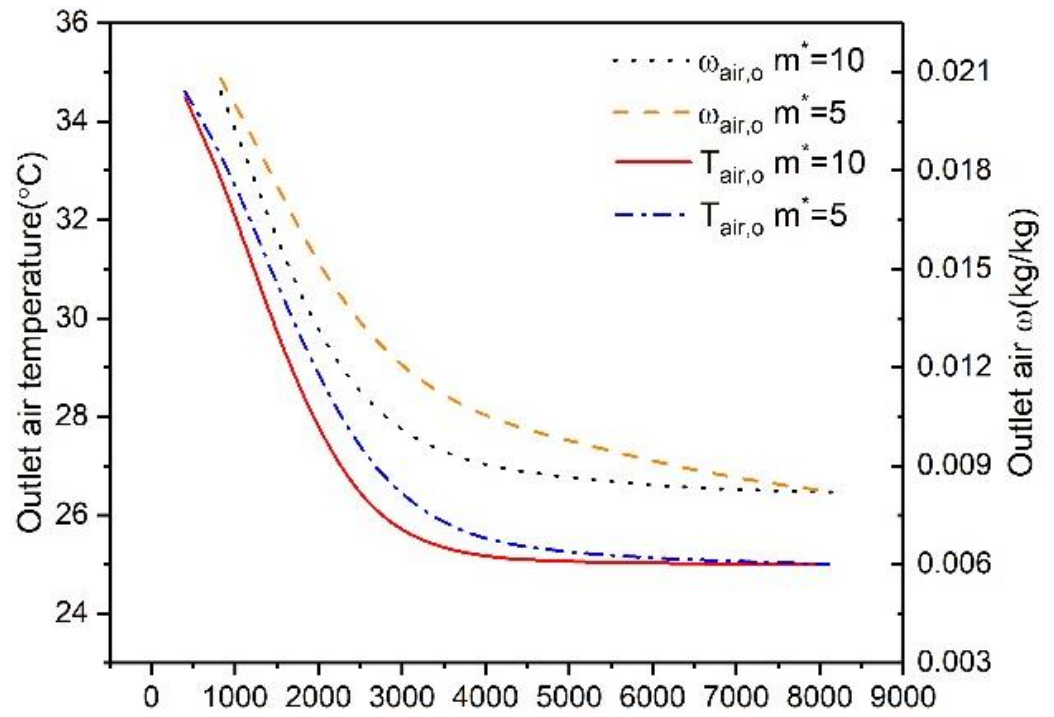

$n_{f}$

656

(B)

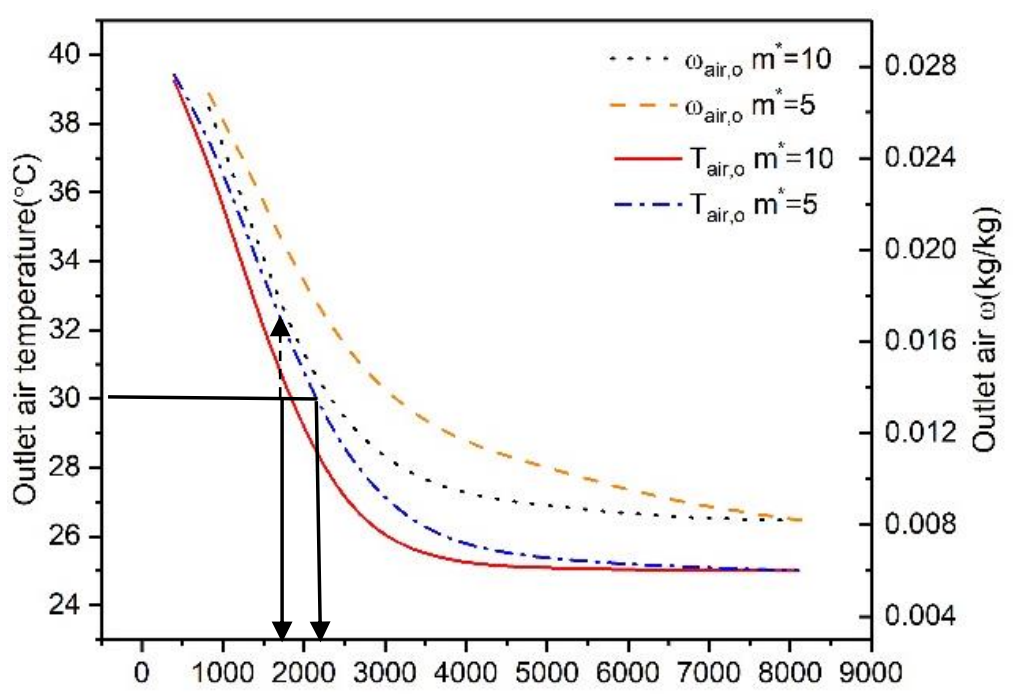

$\mathrm{n}_{\mathrm{f}}$

(C) 
658

659

660

661

662

663

Fig. 16 The variations of outlet air temperature and specific humidity under various fiber numbers with $\dot{m}_{\text {sol }} / \dot{m}_{\text {air }}=10$ and $\dot{m}_{\text {sol }} / \dot{m}_{\text {air }}=5$ and inlet air temperature of (A) $\mathrm{T}_{\text {air, }}=$ $30^{\circ} \mathrm{C}(\mathrm{B}) \mathrm{T}_{\text {air },}=35^{\circ} \mathrm{C}(\mathrm{C}) \mathrm{T}_{\text {air }, i}=40^{\circ} \mathrm{C}$

Table 7 Variations of sensible effectiveness, latent effectiveness and outlet air conditions under various fiber numbers and $\dot{m}_{\text {sol }} / \dot{m}_{\text {air }}$ ratio $\left(\mathrm{T}_{\text {air },}=35^{\circ} \mathrm{C}, \omega_{\text {air }, i}=0.0215 \mathrm{~kg} / \mathrm{kg}, \mathrm{T}_{\text {sol, },}=25^{\circ} \mathrm{C}\right)$

\begin{tabular}{|c|c|c|c|c|c|c|c|}
\hline \multirow{2}{*}{$\begin{array}{c}\text { Number of } \\
\text { fibers in } \\
\text { the module } \\
n_{\mathrm{f}}\end{array}$} & \multirow{2}{*}{$\begin{array}{c}\text { Inlet air } \\
\begin{array}{c}\text { mass flow } \\
\text { rate }\end{array} \\
\dot{m}_{\text {air }}(\mathrm{kg} / \mathrm{s}) \\
\end{array}$} & \multirow{2}{*}{$\begin{array}{l}\text { Mass flow rate } \\
\text { ratio between } \\
\text { inlet solution } \\
\text { and inlet air } \\
\dot{m}_{\text {sol }} / \dot{m}_{\text {air }}\end{array}$} & \multicolumn{5}{|c|}{ Outlet air conditions and associated effectiveness } \\
\hline & & & $\mathrm{T}_{\text {air }, \mathrm{o}}\left({ }^{\circ} \mathrm{C}\right)$ & $\mathrm{T}_{\mathrm{sol}, \mathrm{o}}\left({ }^{\circ} \mathrm{C}\right)$ & $\omega_{\text {air }, \mathrm{o}}(\mathrm{kg} / \mathrm{kg})$ & $\varepsilon_{\mathrm{sen}}$ & $\varepsilon_{\text {lat }}$ \\
\hline \multirow{4}{*}{400} & 0.0087 & 10 & 34.49 & 25.30 & 0.0204 & 0.051 & 0.083 \\
\hline & 0.0174 & 5 & 34.61 & 25.40 & 0.0208 & 0.039 & 0.053 \\
\hline & 0.087 & 1 & 34.80 & 27.62 & 0.0213 & 0.020 & 0.015 \\
\hline & 0.174 & 0.5 & 34.85 & 26.06 & 0.0214 & 0.015 & 0.008 \\
\hline \multirow{4}{*}{900} & 0.0087 & 10 & 32.65 & 25.74 & 0.0172 & 0.235 & 0.323 \\
\hline & 0.0174 & 5 & 33.19 & 26.09 & 0.0186 & 0.181 & 0.218 \\
\hline & 0.087 & 1 & 34.10 & 30.07 & 0.0205 & 0.090 & 0.075 \\
\hline & 0.174 & 0.5 & 34.36 & 28.10 & 0.0209 & 0.064 & 0.045 \\
\hline \multirow{4}{*}{1600} & 0.0087 & 10 & 29.08 & 26.13 & 0.0129 & 0.592 & 0.647 \\
\hline & 0.0174 & 5 & 30.24 & 26.81 & 0.0151 & 0.476 & 0.481 \\
\hline & 0.087 & 1 & 32.60 & 31.32 & 0.019 & 0.240 & 0.188 \\
\hline & 0.174 & 0.5 & 33.38 & 30.68 & 0.02 & 0.162 & 0.113 \\
\hline \multirow{4}{*}{2500} & 0.0087 & 10 & 26.02 & 26.32 & 0.0101 & 0.898 & 0.857 \\
\hline & 0.0174 & 5 & 27.03 & 27.26 & 0.0122 & 0.797 & 0.699 \\
\hline & 0.087 & 1 & 30.41 & 31.83 & 0.0174 & 0.459 & 0.308 \\
\hline & 0.174 & 0.5 & 31.90 & 32.73 & 0.0189 & 0.310 & 0.195 \\
\hline \multirow{4}{*}{3600} & 0.0087 & 10 & 25.16 & 26.39 & 0.009 & 0.984 & 0.940 \\
\hline & 0.0174 & 5 & 25.56 & 27.45 & 0.0122 & 0.944 & 0.827 \\
\hline & 0.087 & 1 & 28.19 & 32.07 & 0.016 & 0.681 & 0.414 \\
\hline & 0.174 & 0.5 & 30.05 & 33.86 & 0.018 & 0.495 & 0.263 \\
\hline \multirow{4}{*}{4900} & 0.0087 & 10 & 25.05 & 26.42 & 0.0086 & 0.995 & 0.970 \\
\hline & 0.0174 & 5 & 25.24 & 27.52 & 0.0097 & 0.976 & 0.887 \\
\hline & 0.087 & 1 & 26.83 & 32.46 & 0.0149 & 0.817 & 0.496 \\
\hline & 0.174 & 0.5 & 28.32 & 34.42 & 0.0172 & 0.668 & 0.323 \\
\hline \multirow{4}{*}{6400} & 0.0087 & 10 & 25.01 & 26.49 & 0.0083 & 0.999 & 0.992 \\
\hline & 0.0174 & 5 & 25.09 & 27.67 & 0.0088 & 0.991 & 0.955 \\
\hline & 0.087 & 1 & 26.32 & 33.31 & 0.0132 & 0.868 & 0.624 \\
\hline & 0.174 & 0.5 & 27.52 & 35.31 & 0.0157 & 0.748 & 0.436 \\
\hline \multirow{4}{*}{8100} & 0.0087 & 10 & 25.00 & 26.56 & 0.0082 & 1.000 & 1.000 \\
\hline & 0.0174 & 5 & 25.00 & 27.90 & 0.0082 & 1.000 & 1.000 \\
\hline & 0.087 & 1 & 26.00 & 34.69 & 0.0103 & 0.900 & 0.842 \\
\hline & 0.174 & 0.5 & 27.15 & 37.57 & 0.0121 & 0.785 & 0.707 \\
\hline
\end{tabular}




\section{Conclusions}

This paper has reported a numerical model for a novel hollow fiber liquid desiccant dehumidification system. A thorough validation demonstrated that the modelled outlet parameters (temperature and specific humidity) for both the processed air and desiccant solution, and the heat and mass transfers under various testing situations were consistent with experimental results, analytical solutions, and results from the literature. Following its successful validation, the model was then used to predict the working performance of the dehumidifier. The effect of inlet parameters (inlet air velocity, inlet air specific humidity, inlet solution temperature, inlet solution concentration, inlet solution mass flow rate) and the air to solution specific humidity ratio on the sensible effectiveness, latent effectiveness and total effectiveness were parametrically assessed. The relationship between NTU and the sensible effectiveness, $\mathrm{NTU}_{\mathrm{m}}$ and the latent effectiveness were also investigated. In addition, the temperature and humidity ratio contour for the air and solution were studied. The main conclusions of this paper can be summarized as follows:

(1) The effects of $\mathrm{Cr}^{*}$ and $\mathrm{NTU}, \mathrm{m}^{*}$ and $\mathrm{NTU}_{\mathrm{m}}$ on the sensible effectiveness and latent effectiveness are obvious. The sensible effectiveness has changed remarkably (from 0.35 to 1 ) with the increase of NTU in the range of 0.47 to $7\left(\mathrm{Cr}^{*}=0.13\right)$. Meanwhile, the latent effectiveness has also changed remarkably with the increase of $\mathrm{NTU}_{\mathrm{m}}$ in the range of 0 to 12 , when $\mathrm{m}^{*}$ is 0.75 .

(2) The increase in inlet air velocity will lead to the drop in sensible effectiveness, latent effectiveness, the inlet and outlet air temperature difference, and the inlet and outlet air relative humidity difference. As the incoming air velocity increases in the range of $1.5 \mathrm{~m} / \mathrm{s}$ to $4.5 \mathrm{~m} / \mathrm{s}$, the sensible effectiveness drops from 0.74 to 0.08 , and latent effectiveness decreases from 0.58 to 0.14 . The sensible effectiveness is more sensitive to the solution inlet temperature, solution mass flow rate and solution concentration. The influences of the solution mass flow rate and the solution concentration on the latent effectiveness are less important in comparison with the sensible effectiveness.

(3) The moisture removal rate and air humidity ratio difference substantially grow with the increase of the $\omega_{r}^{*}$. As the $\omega_{r}^{*}$ increases from 1.45 to 2.15 , the sensible effectiveness decreases from 0.77 to 0.54 , while the total effectiveness drops from 0.59 to 0.65 . The changing $\omega_{r}^{*}$ has a very limited effect on the latent effectiveness.

(4) The increase of solution inlet temperature leads to a drop of sensible effectiveness, while the latent effectiveness remains more or less constant. For instance, as the solution inlet temperature rises from $20.5^{\circ} \mathrm{C}$ to $28.5^{\circ} \mathrm{C}$, the sensible effectiveness declines from 0.37 to 0.17 . Hence, a good way to achieve higher sensible effectiveness without affecting the latent effectiveness could be by decreasing the solution concentration.

(5) At $62 \%$ solution concentration, the latent effectiveness is about 0.47 when the inlet air velocity and solution mass flow rate is $0.087 \mathrm{~kg} / \mathrm{s}$, which is comparable to the value obtained from the literature when $\mathrm{LiCl}$ was the desiccant[57] . Therefore, in order to achieve a similar dehumidification effect as in that case, a higher concentration of $\mathrm{KCOOH}$ desiccant solution should be used.

(6) The influence of fiber numbers on the dehumidification effectiveness, outlet air temperature and relative humidity have been analyzed and the results have been summarized in a user- 
friendly table format. Without performing the iterative modelling, this Table can offer guidance to the designer for selecting the relevant solution to air mass flow ratio and fibers number, according to the required dehumidification effectiveness of the PHDF.

\section{Acknowledgement}

The authors greatly appreciate the financial contributions from the British funding body, Innovate UK (project code: 131821).

\section{References}

1. Artola, I., Boosting Building Renovation: What Potential and Value for Europe? : Study. 2016: European Parliament.

2. Isaac, M. and D.P. van Vuuren, Modeling global residential sector energy demand for heating and air conditioning in the context of climate change. Energy Policy, 2009. 37(2): p. 507-521.

3. Hitchin, R., C. Pout, and P. Riviere, Assessing the market for air conditioning systems in European buildings. Energy and Buildings, 2013. 58: p. 355-362.

4. Chua, K.J., et al., Achieving better energy-efficient air conditioning - A review of technologies and strategies. Applied Energy, 2013. 104: p. 87-104.

5. Chen, X., et al., Experimental investigations of polymer hollow fibre integrated evaporative cooling system with the fibre bundles in a spindle shape. Energy and Buildings, 2017. 154: p. 166-174.

6. Chen, X., et al., A novel evaporative cooling system with a polymer hollow fibre spindle. Applied Thermal Engineering, 2018. 132: p. 665-675. 
734 7. Peng, D. and X. Zhang, An analytical model for coupled heat and mass transfer processes in solar collector/regenerator using liquid desiccant. Applied Energy, 2011. 88(7): p. 2436-2444.

8. Li, X., et al., Dynamic modeling of a liquid desiccant dehumidifier. Applied Energy, 2016. 180: p. $435-445$.

9. Xiao, F., G. Ge, and X. Niu, Control performance of a dedicated outdoor air system adopting liquid desiccant dehumidification. Applied Energy, 2011. 88(1): p. 143-149.

10. Keniar, K., K. Ghali, and N. Ghaddar, Study of solar regenerated membrane desiccant system to control humidity and decrease energy consumption in office spaces. Applied Energy, 2015. 138: p. 121-132.

11. Gao, W.Z., et al., Experimental study on partially internally cooled dehumidification in liquid desiccant air conditioning system. Energy and Buildings, 2013. 61: p. 202-209.

12. Yin, Y., et al., Experimental study on a new internally cooled/heated dehumidifier/regenerator of liquid desiccant systems. International Journal of Refrigeration, 2008. 31(5): p. 857-866.

13. Luo, Y., et al., Experimental study of internally cooled liquid desiccant dehumidification: Application in Hong Kong and intensive analysis of influencing factors. Building and Environment, 2015. 93: p. 210-220.

14. Bansal, P., S. Jain, and C. Moon, Performance comparison of an adiabatic and an internally cooled structured packed-bed dehumidifier. Applied Thermal Engineering, 2011. 31(1): p. 14-19. 
755 15. Song, X., L. Zhang, and X. Zhang, NTUm-based optimization of heat or heat pump

756

757

758

759

760

761

762

763

764

765

766

767

768

769

770

771

772

773

774

775

driven liquid desiccant dehumidification systems regenerated by fresh air or return air. Energy, 2018. 158: p. 269-280.

16. Wang, X., et al., A hybrid dehumidifier model for real-time performance monitoring, control and optimization in liquid desiccant dehumidification system. Applied Energy, 2013. 111: p. 449-455.

17. Wu, Q., et al., A regulation strategy of working concentration in the dehumidifier of liquid desiccant air conditioner. Applied Energy, 2017. 202: p. 648-661.

18. Zhang, L., H. Wei, and X. Zhang, Theoretical analysis of heat and mass transfer characteristics of a counter-flow packing tower and liquid desiccant dehumidification systems based on entransy theory. Energy, 2017. 141: p. 661-672.

19. Kumar, R., et al., Multi absorber stand alone liquid desiccant air-conditioning systems for higher performance. Solar Energy, 2009. 83(5): p. 761-772.

20. Das, R.S. and S. Jain, Experimental performance of indirect air-liquid membrane contactors for liquid desiccant cooling systems. Energy, 2013. 57: p. 319-325.

21. Bai, H., et al., Influences of the mixed LiCl-CaCl2 liquid desiccant solution on a membrane-based dehumidification system: Parametric analysis and mixing ratio selection. Energy and Buildings, 2019. 183: p. 592-606.

22. Xiong, Z.Q., Y.J. Dai, and R.Z. Wang, Development of a novel two-stage liquid desiccant dehumidification system assisted by CaCl2 solution using exergy analysis method. Applied Energy, 2010. 87(5): p. 1495-1504. 
776

23. Luo, Y., et al., Experimental and theoretical research of a fin-tube type internally-cooled liquid desiccant dehumidifier. Applied Energy, 2014. 133: p. 127-134.

24. Luo, Y., et al., Study on an internally-cooled liquid desiccant dehumidifier with CFD model. Applied Energy, 2017. 194: p. 399-409.

25. Ou, X., et al., Experimental investigations on heat and mass transfer performances of a liquid desiccant cooling and dehumidification system. Applied Energy, 2018. 220: p. 164-175.

26. Das, R.S. and S. Jain, Performance characteristics of cross-flow membrane contactors for liquid desiccant systems. Applied Energy, 2015. 141: p. 1-11.

27. Ge, G., et al., Comparison of experimental data and a model for heat and mass transfer performance of a liquid-to-air membrane energy exchanger (LAMEE) when used for air dehumidification and salt solution regeneration. International Journal of Heat and Mass Transfer, 2014. 68: p. 119-131.

28. Ge, G., et al., Analytical model based performance evaluation, sizing and coupling flow optimization of liquid desiccant run-around membrane energy exchanger systems. Energy and Buildings, 2013. 62: p. 248-257.

29. Moghaddam, D.G., et al., Small-scale single-panel liquid-to-air membrane energy exchanger (LAMEE) test facility development, commissioning and evaluating the steady-state performance. Energy and Buildings, 2013. 66: p. 424-436.

30. Ge, G., et al., Comparison of experimental data and a model for heat and mass transfer performance of a liquid-to-air membrane energy exchanger (LAMEE) when used for air 
dehumidification and salt solution regeneration. International Journal of Heat \& Mass Transfer, 2014. 68(1): p. 119-131.

31. Ghadiri Moghaddam, D., R.W. Besant, and C.J. Simonson, Solution-side effectiveness for a liquid-to-air membrane energy exchanger used as a dehumidifier/regenerator. Applied Energy, 2014. 113: p. 872-882.

32. Ghadiri Moghaddam, D., R.W. Besant, and C.J. Simonson, A methodology for scaling a small-scale energy exchanger performance results to a full-scale energy exchanger. International Journal of Heat and Mass Transfer, 2015. 82: p. 555-567.

33. Namvar, R., et al., Transient heat and moisture transfer characteristics of a liquid-to-air membrane energy exchanger (LAMEE) model verification and extrapolation. International Journal of Heat and Mass Transfer, 2013. 66: p. 757-771.

34. Moghaddam, D.G., R.W. Besant, and C.J. Simonson, Solution-side effectiveness for a liquid-to-air membrane energy exchanger used as a dehumidifier/regenerator. Applied Energy, 2014. 113(6): p. 872-882.

35. Chen, X., et al., Recent research developments in polymer heat exchangers - A review. Renewable and Sustainable Energy Reviews, 2016. 60: p. 1367-1386.

36. Zhang, L.-Z., et al., Conjugate heat and mass transfer in a hollow fiber membrane module for liquid desiccant air dehumidification: $A$ free surface model approach. International Journal of Heat and Mass Transfer, 2012. 55(13-14): p. 3789-3799.

37. Huang, S.M., et al., Fluid flow and heat mass transfer in membrane parallel-plates channels used for liquid desiccant air dehumidification. International Journal of Heat \& Mass Transfer, 2012. 55(9-10): p. 2571-2580. 
819 38. Li, Z.X. and L.Z. Zhang, Flow maldistribution and performance deteriorations in a counter flow hollow fiber membrane module for air humidification/dehumidification. Journal of Membrane Science, 2014. 74(1): p. 421-430.

822 39. Zhang, N., S.-Y. Yin, and L.-Z. Zhang, Performance study of a heat pump driven and

41. Liang, C.-H., L.-Z. Zhang, and L.-X. Pei, Performance analysis of a direct expansion air dehumidification system combined with membrane-based total heat recovery. Energy, 2010. 35(9): p. 3891-3901.

42. Chen, X., et al., Experimental investigations of polymer hollow fibre heat exchangers for building heat recovery application. Energy and Buildings, 2016. 125: p. 99-108.

43. Riffat, S.B., S.E. James, and C.W. Wong, Experimental analysis of the absorption and desorption rates of $\mathrm{HCOOK} / \mathrm{H} 2 \mathrm{O}$ and $\mathrm{LiBr} / \mathrm{H} 2 \mathrm{O}$. International Journal of Energy Research, 1998. 22(12): p. 1099-1103.

44. Chen, X., et al., Experimental investigation of a polymer hollow fibre integrated liquid desiccant dehumidification system with aqueous potassium formate solution. Applied Thermal Engineering, 2018. 142: p. 632-643.

45. Karlsson, H.O.E. and G. Trägårdh, Heat transfer in pervaporation. Journal of Membrane Science, 1996. 119(2): p. 295-306. 
841 46. Zhang, L.Z., Y. Jiang, and Y.P. Zhang, Membrane-based humidity pump: performance and limitations. Journal of Membrane Science, 2000. 171(2): p. 207-216.

843 47. Zhang, L.Z., Heat and mass transfer in a randomly packed hollow fiber membrane module: A fractal model approach. International Journal of Heat \& Mass Transfer, 2011. 54(13): p. 2921-2931.

48. Zhang, L.Z., Fabrication of a lithium chloride solution based composite supported liquid membrane and its moisture permeation analysis. Journal of Membrane Science, 2006.

49. Incropera, F.P. and D.P. DeWitt, Fundamentals of heat and mass transfer, 6th Edition. Wiley, New York, 2006.

50. Seyed-Ahmadi, M., et al., Transient behavior of run-around heat and moisture exchanger system. Part I: Model formulation and verification. International Journal of 
55. Zhang, L.Z. and J.L. Niu, Effectiveness Correlations for Heat and Moisture Transfer Processes in an Enthalpy Exchanger With Membrane Cores. Journal of Heat Transfer, 2002. 124(5): p. 922-929.

56. RK;, S. and S. DP, Fundamental of Heat Exchanger Design. John Wiley \& Sons, Hoboken, NJ, 2003: p. 97-164.

57. Zhang, L.Z., An Analytical Solution to Heat and Mass Transfer in Hollow Fiber Membrane Contactors for Liquid Desiccant Air Dehumidification. Journal of Heat Transfer, 2011. 133(9): p. 092001.

\section{Nomenclature}

$A$

$c_{p}$

$d$

$d_{h}$

$h$

$h_{f g}$

k

L

$M$

$m^{*}$

$\dot{m}$

$m_{\text {sen }}$

$m_{\text {lat }}$

$n$

NTU

$N T U_{m}$

$\mathrm{Nu}$

Sh

Sc

$P_{\text {sol }}$

$P$

$P r$

$R e$

RH

$T$

$u$

X hollow fiber surface area $\left(\mathrm{m}^{2}\right)$ specific heat capacity $(\mathrm{J} / \mathrm{kgK})$

heat capacity ratio

diameter (m)

hydrodynamic diameter $(\mathrm{m})$

convective heat transfer coefficient $\left(\mathrm{W} / \mathrm{m}^{2} \mathrm{~K}\right)$

condensation heat of water $(\mathrm{J} / \mathrm{kg})$

mass transfer coefficient $(\mathrm{m} / \mathrm{s})$

length of the dehumidifier $(\mathrm{m})$

moisture removal rate $(\mathrm{kg} / \mathrm{s})$

solution-to-air-mass flow rate ratio

mass flow rate $(\mathrm{kg} / \mathrm{s})$

sensible heat capacity ratio

latent heat capacity ratio

number of fibres inside the module

number of heat transfer units

number of mass transfer units

Nusselt number

Sherwood number

Schmidt number

equilibrium vapour pressure of desiccant solution $(\mathrm{Pa})$

pressure $(\mathrm{Pa})$

Prandtl number

Reynolds number

relative humidity $(\%)$

temperature $\left({ }^{\circ} \mathrm{C}\right)$

velocity $(\mathrm{m} / \mathrm{s})$

desiccant solution mass fraction ( $\mathrm{kg} \mathrm{KCOOH} / \mathrm{kg}$ solution) 
$\lambda$

$\omega$

$\omega_{r}$

$\varphi$

$\mu$

$\varepsilon$

$\delta$

$\rho$

$v$

$\tau$

$\psi$

\section{Subscripts}

air

atm

$c$

crit

$b$

desi

$e q$

exp

$f$

$h$

$\boldsymbol{i}$

lat

lim

m

num

$\boldsymbol{O}$

$o v$

$s$

sen

sol

tot

w thermal conductivity $(\mathrm{W} / \mathrm{mK})$

specific humidity of the air ( $\mathrm{kg}$ moisture/ $\mathrm{kg}$ air)

air to solution specific humidity ratio

packing fraction

dynamic viscosity $(\mathrm{Pa} \cdot \mathrm{s})$

effectiveness

thickness of hollow fiber (m)

solution density $\left(\mathrm{kg} / \mathrm{m}^{3}\right)$

kinematic viscosity $\left(\mathrm{m}^{2} / \mathrm{s}\right)$

fractal dimension of the fiber module diffusivity $\left(\mathrm{m}^{2} / \mathrm{s}\right)$

air flow

atmospheric pressure

dehumidifier cross section

critical value

bulk

desiccant

equivalent

experimental

fiber

Hydraulic

inlet, inside

latent

limiting value

mass transfer/hollow fiber

numerical

outlet, outside

overall

surface

sensible

solution flow

total

water 